\title{
Assessing biogeochemical effects and best management practice for a wheat-maize cropping system using the DNDC model
}

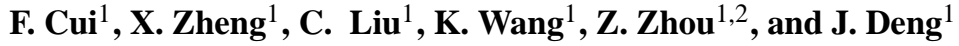 \\ ${ }^{1}$ State Key Laboratory of Atmospheric Boundary Layer Physics and Atmospheric Chemistry, Institute of Atmospheric \\ Physics, Chinese Academy of Sciences, Beijing 100029, China \\ ${ }^{2}$ Institute for the Study of Earth, Oceans, and Space, University of New Hampshire, Durham, NH 03824, USA
}

Correspondence to: X. Zheng (xunhua.zheng@post.iap.ac.cn)

Received: 9 March 2013 - Published in Biogeosciences Discuss.: 22 May 2013

Revised: 23 November 2013 - Accepted: 29 November 2013 - Published: 7 January 2014

\begin{abstract}
Contemporary agriculture is shifting from a single-goal to a multi-goal strategy, which in turn requires choosing best management practice (BMP) based on an assessment of the biogeochemical effects of management alternatives. The bottleneck is the capacity of predicting the simultaneous effects of different management practice scenarios on multiple goals and choosing BMP among scenarios. The denitrification-decomposition (DNDC) model may provide an opportunity to solve this problem. We validated the DNDC model (version 95) using the observations of soil moisture and temperature, crop yields, aboveground biomass and fluxes of net ecosystem exchange of carbon dioxide, methane, nitrous oxide $\left(\mathrm{N}_{2} \mathrm{O}\right)$, nitric oxide (NO) and ammonia $\left(\mathrm{NH}_{3}\right)$ from a wheat-maize cropping site in northern China. The model performed well for these variables. Then we used this model to simulate the effects of management practices on the goal variables of crop yields, NO emission, nitrate leaching, $\mathrm{NH}_{3}$ volatilization and net emission of greenhouse gases in the ecosystem (NEGE). Results showed that no-till and straw-incorporated practices had beneficial effects on crop yields and NEGE. Use of nitrification inhibitors decreased nitrate leaching and $\mathrm{N}_{2} \mathrm{O}$ and NO emissions, but they significantly increased $\mathrm{NH}_{3}$ volatilization. Irrigation based on crop demand significantly increased crop yield and decreased nitrate leaching and $\mathrm{NH}_{3}$ volatilization. Crop yields were hardly decreased if nitrogen dose was reduced by $15 \%$ or irrigation water amount was reduced by $25 \%$. Two methods were used to identify BMP and resulted in the same BMP, which adopted the current crop cultivar, field operation schedules and full straw incorporation and applied nitrogen and irrigation water at 15 and $25 \%$ lower rates,
\end{abstract}

respectively, than the current use. Our study indicates that the DNDC model can be used as a tool to assess biogeochemical effects of management alternatives and identify BMP.

\section{Introduction}

In recent decades, maximum crop yield has been the single target used to assess agricultural success in response to rapid population increase in China. Nitrogen fertilizer(s) have been intensively applied to enhance crop yields (e.g., Ju et al., 2009), leading to severe environmental degradation (Liu and Diamond, 2005, 2008). Environmental degradation is closely linked to the present environmental and climate changes, because fertilized croplands are significant sources or sinks of greenhouse gases, such as, carbon dioxide $\left(\mathrm{CO}_{2}\right)$, methane $\left(\mathrm{CH}_{4}\right)$ and nitrous oxide $\left(\mathrm{N}_{2} \mathrm{O}\right)$. Additionally, these fields are important sources of nitrogen pollutants, such as, nitric oxide $(\mathrm{NO})$, ammonia $\left(\mathrm{NH}_{3}\right)$ and nitrate in water (e.g., IPCC, 2007). In addition to fertilization, other crop production activities, including irrigation, tillage and crop residue management, can also influence the sources and sinks of gases and hydrological nitrogen losses and thus contribute to environmental degradation as well. To produce food in a highly efficient manner with the lowest possible environmental hazards, contemporary agriculture is shifting from a single-goal to a multi-goal strategy. A multi-goal management of an agricultural ecosystem is expected to simultaneously aim for the following four goals: (a) sustaining/enhancing productivity (crop yields) to ensure food security; (b) mitigating net emission of greenhouse gases in the ecosystem (NEGE) 
to combat climate warming; (c) reducing reactive nitrogenous gas emissions, mainly $\mathrm{NH}_{3}$ and $\mathrm{NO}$ to protect the air quality and the climate; and (d) mitigating hydrological nitrogen losses (mainly nitrate leaching) to secure water quality. For an ecosystem with annual vegetation, the net $\mathrm{CO}_{2}$ emission can be referred as the opposite change in soil organic carbon $(-\Delta \mathrm{SOC})$ that is resistant to decomposition and thus remains relatively stable in soils for longer than decade. It is regarded as a source of atmospheric $\mathrm{CO}_{2}$ when $\triangle \mathrm{SOC}$ is negative and a sink when $\triangle \mathrm{SOC}$ is positive. Croplands with submerged soils such as paddy rice fields are usually the sources of atmospheric $\mathrm{CH}_{4}$, while uplands such as wheat and maize fields are often sinks (Dutaur and Verchot, 2007; IPCC, 2007). Nitrogen-fertilized croplands are important sources of atmospheric $\mathrm{N}_{2} \mathrm{O}$ (IPCC, 2007). For an ecosystem with annual vegetation, the quantities of $-\Delta \mathrm{SOC}$ and net $\mathrm{CH}_{4}$ and $\mathrm{N}_{2} \mathrm{O}$ emissions for a given timescale are usually converted to $\mathrm{CO}_{2}$ equivalents using the global warming potentials ( 1 for $\mathrm{CO}_{2}, 25$ for $\mathrm{CH}_{4}$ and 298 for $\mathrm{N}_{2} \mathrm{O}$ at the 100-year time horizon; IPCC, 2007). The equivalents are then added together to express the NEGE. Fertilized croplands are also important sources of atmospheric $\mathrm{NH}_{3}$ and $\mathrm{NO}$ and nitrogen in aquatic ecosystems. Nitrogen-fertilizer losses by $\mathrm{NH}_{3}$ volatilization and nitrate leaching also lead to a reduction in nitrogen use efficiency (Zhu and Chen, 2002; Yan et al., 2003). The conversion of $\mathrm{NO}_{\mathrm{x}}(\mathrm{NO}$ and nitrogen dioxide) to nitric acid vapor that reacts further with $\mathrm{NH}_{3}$ can form secondary aerosols (eg., ammonium nitrate particles, organic aerosol particles if VOC is involved) (EPA, 2004), which in turn can affect human health and climate forcing (IPCC, 2007). Besides, $\mathrm{NO}_{\mathrm{x}}$ and $\mathrm{NH}_{3}$ also greatly contribute to atmospheric nitrogen deposition, which in turn can influence biodiversity and nitrogen cycling in natural ecosystems (Galloway et al., 1994; Aneja et al., 2001). Nitrogen loading into aquatic ecosystems can damage water quality and cause eutrophication (Tilman et al., 2002; Seitzinger, 2008). As a consequence, other goals in addition to crop yields must simultaneously be taken into account during assessments of agricultural management practices (Tilman et al., 2002).

In China, winter wheat and summer maize have been commonly cultivated in rotation (with both crops harvested in the same year) for decades in regions characterized by northern subtropical and southern temperate climates (Tong et al., 2003; Liu et al., 2012). Single-goal (i.e., yield) management is being adopted for wheat and maize production in the southern temperate region (northern China); consequently, the current crop yields are obtained mostly by high rates of nitrogen application coupled with high water input from irrigation (Wang et al., 2008; Ju et al., 2009). However, single-goal management is obviously not environmentally friendly and thus unsustainable because of low nitrogen use efficiencies (Zhao et al., 2006; Jia et al., 2004) and very limited water resources for irrigation (Liu et al., 2001). Therefore, it is very important to convert the single-goal management to multigoal management for wheat and maize cultivation in northern
China. Best management practice (BMP) is required, which include the assessment of biogeochemical effects of different alternatives, i.e., fertilization, tillage, irrigation and crop residue treatment.

There are two challenges of identifying a BMP. One is how to quantify the biogeochemical effects of various management alternatives on the multiple goals stated above, and the other is how to identify the BMP from these management alternatives. Field experiments have played a key role in determining management practice effects. These experiments have indicated that no-till and crop residue applications are usually favorable for carbon sequestration, i.e., as a $\mathrm{CO}_{2}$ sink (Schlesinger, 1999; Grandy et al., 2006). However, the effects of these practices on $\mathrm{N}_{2} \mathrm{O}$ and $\mathrm{NO}$ emissions are contradictory. Some experimental studies have reported positive effects for tillage on the emissions of $\mathrm{N}_{2} \mathrm{O}$ (Estavillo et al., 2002) and NO (Yao et al., 2009), while others have found inhibitory or no obvious effects (Grandy et al., 2006). The effects of crop straw incorporation on $\mathrm{N}_{2} \mathrm{O}$ and $\mathrm{NO}$ emissions have been found to be dependent on the use of chemical fertilizers as well as straw quantity and quality (Baggs et al., 2003; Liu et al., 2011; Yao et al., 2009). Ammonia volatilization has been observed at much lower levels when urea is deeply buried in soils or used together with a urease inhibitor in comparison with surface broadcasting or without a urease inhibitor (Roelcke et al., 2002; Cai et al., 2002). Ammonia volatilization may have also been influenced by fertilizer types and crop residue applications (Roelcke et al., 2002; Francisco et al., 2011). Irrigation methods, as well as rates and times of fertilizer application, have been reported to affect nitrate leaching (Goulding, 2000; Di and Cameron, 2002). Researchers have observed stimulatory, inhibitory or no obvious effects of nitrogen application rates on $\mathrm{CH}_{4}$ uptake by upland agricultural soils (Bodelier and Laanbroek, 2004; Aronson and Helliker, 2010). To date, however, field experiments such as those reviewed above have focused on single or very few of our goals, or they have focused on these effects over very short periods for many reasons, such as resource limitations. This suggests that field experiments alone are hard to quantify the biogeochemical effects of different management alternatives on multiple goals. In order to overcome this, process-based models can be used, such as DNDC (Li et al., 1992; Li, 2000), DAYCENT (Parton et al., 1994) and WNMM (Li et al., 2007). Because the DNDC model has been widely tested and applied to various croplands in China to simulate greenhouse gas emissions (e.g., Li et al., 2010), SOC dynamics (e.g., Zhang et al., 2006) and crop yields (e.g., Liang et al., 2011), in this study we choose it as an attempt to quantify the biogeochemical effects for the wheat-maize cropping system in northern China.

To identify a BMP from management scenarios is also difficult because it is hard to evaluate the comprehensive effects of the multiple goal variables. Farahbakhshazad et al. (2008) reported a subjective method by combining the single-factorial practices with the maximum benefits (as 
compared to the baseline scenario) in terms of the goal variables they concerned. This method can be applicable for relatively simple situations involving a small number of management scenarios, with consistently positive or negative effects for most of the goal variables. Otherwise, such a subjective method can be hardly applied. Therefore, it is necessary to develop an objective method that is expected to be applicable for complicate cases with, for example, more goal variables, a much larger number of scenarios and more complex responses of the goal variable to alternation of management practices.

The DNDC model links ecological drivers (e.g., climate, soil properties, vegetation and anthropogenic activities) to soil environmental variables (e.g., temperature and moisture). These variables in turn regulate carbon and nitrogen transformation processes by which the variables of our multiple goals (i.e., crop yield, $\triangle \mathrm{SOC}$, nitrate leaching and emissions of $\mathrm{NH}_{3}, \mathrm{CH}_{4}, \mathrm{~N}_{2} \mathrm{O}$ and $\mathrm{NO}$ ) were simulated. Although the DNDC has been used widely for both croplands and grasslands under a broad range of conditions (e.g., Brown et al., 2002; Cai et al., 2003; Kesik et al., 2005; Babu et al., 2006; Wang et., 2012), validation data were usually limited to single or very few goals that relate to our goals (Giltrap et al., 2010a). An ideal application of this model in establishing BMP should include validation against observations of the following: (a) crop growth or yield, (b) soil climate, (c) $\triangle \mathrm{SOC}$ and/or carbon fluxes, (d) nitrogen fluxes and (e) water balance (Tonitto et al., 2010). In reality, few observations can simultaneously include these five aspects.

To identify BMP for the wheat-maize cropping system in northern China, we conducted a modeling case study at a wheat-maize rotation field site in the Shanxi province, where simultaneous observations of soil climate, crop growth and yields, net ecosystem exchange of $\mathrm{CO}_{2}$ (NEE), and $\mathrm{CH}_{4}$, $\mathrm{NH}_{3}, \mathrm{~N}_{2} \mathrm{O}$ and $\mathrm{NO}$ fluxes were available. Our objectives were to (a) validate the DNDC model (version 95) using simultaneous observations, (b) use model simulation to evaluate the biogeochemical effects of alternative management practices, and (c) identify the BMP aiming at our four goals stated above.

\section{Materials and methods}

\subsection{Description of the field site}

The field site $\left(34^{\circ} 55.51^{\prime} \mathrm{N}, 110^{\circ} 42.59^{\prime} \mathrm{E}\right)$ for this modeling case study is located at Dongcun farm, Shanxi province in northern China. This region has a temperate continental climate. Winter wheat and summer maize ration dominates the crop cultivation systems of this farm and its nearby areas. The mean annual air temperature and precipitation in 19862010 at the Yuncheng meteorological station (approximately $60 \mathrm{~km}$ away from the field site) were $14.4{ }^{\circ} \mathrm{C}$ and $580 \mathrm{~mm}$, respectively (National Climate Data, ftp://ftp.ncdc.noaa.gov/ pub/data/gsod/). The soil at the study site has a clay loam texture with $31.8 \pm 0.9 \%$ clay $(<0.002 \mathrm{~mm}), 38.9 \pm 0.6 \%$ silt $(0.002-0.02 \mathrm{~mm})$ and $29.3 \pm 1.4 \%$ sand $(0.02-2 \mathrm{~mm})$ in the uppermost $10 \mathrm{~cm}$ layer (Liu et al., 2011, 2012). The soil $(0-10 \mathrm{~cm})$ contains organic carbon of $11.3 \pm 0.6 \mathrm{~g} \mathrm{~kg}^{-1}$, total nitrogen of $1.12 \pm 0.05 \mathrm{~g} \mathrm{~kg}^{-1}, \mathrm{pH}\left(\mathrm{H}_{2} \mathrm{O}\right)$ of 8.7 and has a bulk density (0-6 cm) of $1.17 \pm 0.04 \mathrm{~g} \mathrm{~cm}^{-3}$ (Liu et al., 2011, 2012).

\subsection{Description of the DNDC model}

The DNDC model (version 95), downloaded from web (http: //www.globaldndc.net/) in April 2012, is a process-based model, which was originally developed to estimate the $\mathrm{N}_{2} \mathrm{O}$ emissions from U.S. agricultural fields (Li et al., 1992) and later extended to estimate other carbon and nitrogen processes such as $\mathrm{NO}, \mathrm{CH}_{4}$ and $\mathrm{NH}_{3}$ emissions, SOC dynamics and crop yields ( $\mathrm{Li}$ et al., 1996; $\mathrm{Li}, 2000$ ). This model is composed of two components. One consists of the climate, crop and decomposition submodels and calculates the states of the soil-plant system such as soil chemical and physical status, vegetation growth and organic carbon mineralization. This calculation is driven by environmental and anthropogenic drivers (daily weather, soil properties and farm management practices). The other component consists of nitrification, denitrification and fermentation submodels. The DNDC model predicts $\mathrm{NO}, \mathrm{N}_{2} \mathrm{O}, \mathrm{CH}_{4}$ and $\mathrm{NH}_{3}$ fluxes that are regulated by soil environmental variables and substrates, which are calculated by the former component. $\mathrm{Li}$ (2000) detailed the structures, equations and parameters of this model. This model can perform simulations at the site or regional scale, and simulations with the site mode enable comparison against field observations.

To carry out simulations at the site scale, the model requires inputs of daily meteorological data (e.g., maximum/minimum temperatures and precipitation), soil properties (e.g., texture, SOC content, $\mathrm{pH}$ and bulk density) and management practices (e.g., crop information, tillage, fertilization and irrigation). Although the model provides default values for these parameters in relation to the inputs, it is better to substitute them with measured data or to calibrate them using other easily obtained data. Any change in either the natural conditions or the farming management practices can alter the soil environmental status and substrate contents and thus the biogeochemical reactions, thereby altering crop growth, carbon balance, carbon and nitrogen gas emissions and nitrate leaching. Therefore, the model can simultaneously simulate yield, $\triangle \mathrm{SOC}, \mathrm{CH}_{4}, \mathrm{~N}_{2} \mathrm{O}$ and $\mathrm{NO}$ emissions, $\mathrm{NH}_{3}$ volatilization and nitrate leaching under different management practices.

\subsection{Data for model validation}

Two groups of data were prepared to validate the model. One was for the model simulation inputs and included daily 
meteorological data (maximum/minimum temperature and precipitation), soil properties (texture, clay fraction, bulk density, $\mathrm{pH}, \mathrm{SOC}$ content, field capacity and wilting point), crop parameters (accumulated temperature, mass fractions of plant organs and carbon to nitrogen ratios of plant organs) and data for management operation (tillage, fertilization and irrigation). The other group was used to validate the model outputs for variables of interest. This group included data about the soil climate (soil temperature and moisture), biomass dynamics and crop yields, NEE fluxes, $\mathrm{CH}_{4}, \mathrm{~N}_{2} \mathrm{O}$, $\mathrm{NH}_{3}$ and $\mathrm{NO}$ emissions and others. We used daily meteorological data during 2003-2010 to drive model simulations for validation purposes, of which those from 2008 to 2010 were measured at the field site and the others were obtained at the Yuncheng meteorological station (ftp://ftp.ncdc.noaa. gov/pub/data/gsod/). All soil property data, excluding field capacity and wilting point, were measured at the field site and are given in Sect. 2.1. The model provides default values for field capacity and wilting point once the soil texture is determined. We calibrated these values with our measured soil moisture data from January 2008 to October 2008 (Table 1, Fig. 1), which resulted in 0.65 and 0.20 , respectively. The model also provides defaults for crop parameters. Because these parameters are usually cultivar- or site specific (Ludwig et al., 2011) and they are crucial for simulating crop growth, we substituted them with field site observations or values from literature. Specifically, the root mass fraction was set as 0.10 for both wheat and maize according to Huang et al. (2009), while the mass fractions of grain (wheat, 0.38; maize, 0.40) and leaf + stem (wheat, 0.52; maize, 0.50 ) were given as the field observation averages (unpublished data from the authors). Carbon to nitrogen ratios for grain and leaf + stem were set as 20 and 80 for wheat and 30 and 50 for maize according to observations from multiple field treatments listed in Table 1 (unpublished data from the authors). The carbon to nitrogen ratios of the roots were assumed to be the same with those of leaf + stem for both crops. Unpublished data of grain and leaf + stem and their carbon to nitrogen ratios were measured at harvest, using the method described by Liu et al. (2012). The model default values for the accumulated temperature (thermal degree days) from seeding to maturity were substituted with $1800^{\circ} \mathrm{C}\left(>9.5^{\circ} \mathrm{C} \mathrm{d}^{-1}\right)$ and $2900^{\circ} \mathrm{C}\left(>0{ }^{\circ} \mathrm{C} \mathrm{d}^{-1}\right)$ for wheat and maize, respectively, using $10 \mathrm{yr}$ averages from temperatures measured from 2001 to 2010 at the Yuncheng meteorological station (ftp://ftp.ncdc.noaa.gov/pub/data/gsod/). We directly used the model default values for those soil and crop parameters if not specifically mentioned above. To simulate the effects of nitrification inhibitors, the efficiency and the effective duration was set as 0.6 and 30 days for dicyandiamide, and 0.9 and 30 days for 3, 4-dimethyl pyrazole phosphate according to model validation using measured data of $\mathrm{N}_{2} \mathrm{O}$ and $\mathrm{NO}$ emissions.

To validate the model outputs, we used the measured data of soil $(5 \mathrm{~cm})$ temperature and topsoil $(0-6 \mathrm{~cm})$ moisture
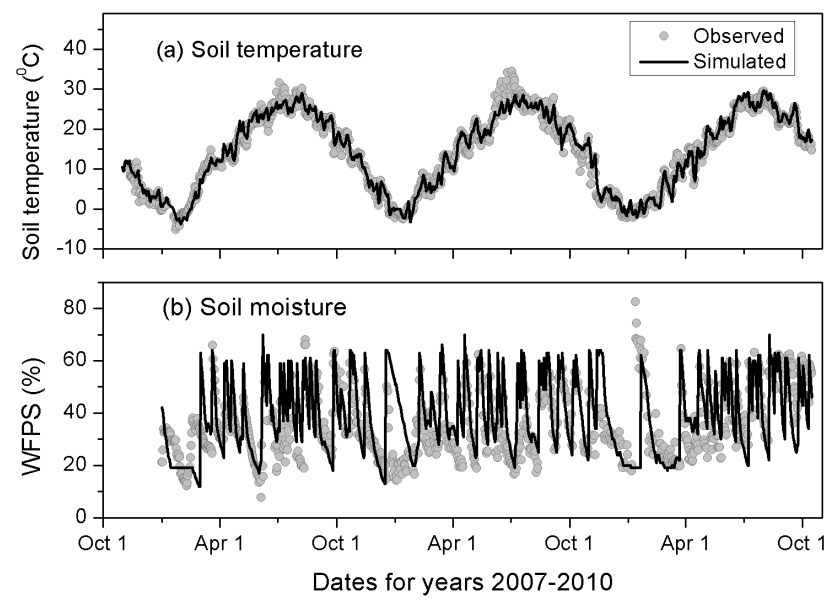

Fig. 1. Observed and simulated daily mean soil $(5 \mathrm{~cm})$ temperature and soil $(0-6 \mathrm{~cm})$ moisture contents in water-filled pore space (WFPS) from October 2007 to October 2010. Measurements (moisture) from January 2008 to October 2008 were used for parameter calibration and the remaining observations were used for validation. The observed data were adapted from Liu et al. $(2011,2012)$.

from 2007 to 2010 (Liu et al., 2011, 2013), grain yields from 2005 to 2010 (Liu et al., 2011, 2012, 2013), aboveground biomass dynamics from 2008 to 2010 (unpublished data from the authors), NEE from April 2009 to April 2010 (Wang et al., 2013; unpublished data from the authors), $\mathrm{CH}_{4}$ fluxes from 2009 to 2010 (Liu et al., 2012), and emissions of $\mathrm{N}_{2} \mathrm{O}$ (Liu et al., 2011, 2012, 2013) and NO (Liu et al., 2011: 2008-2009; others were unpublished data from the authors) from 2008 to 2010 from different treatments at the wheatmaize rotation field (Table 1). Unpublished data of aboveground biomass dynamics that were weekly measured since winter wheat reviving or summer maize germination were measured at harvest, using the method described by Liu et al. (2012). The NEE data during the non-maize period were cited from Wang et al. (2013), and those during the maize growing period were measured with the eddy covariance technique as described by Wang et al. (2013). The unpublished NO data were measured by the static opaque chamber/chemoluminescence method as described in previous studies (Liu et al., 2011; Cui et al., 2012; Mei et al., 2009). In addition to data listed in Table1, fluxes of $\mathrm{NH}_{3}$ volatilization following a nitrogen fertilization event in the field adjacent to the experimental plot of the conventional management treatment (CT) were adapted from Yang et al. (2011) and used to validate the model as well. From 2005 to 2008, observations were available for CT and improved management treatment (IT). In addition to the different nitrogen addition rates between the two treatments, flooding irrigation was adapted for CT and sprinkler irrigation for IT. From 2008 to 2009, the data were collected from with-straw (WS) and no-straw (NS) incorporation treatments. From 2009 to 2010, observations were performed for the treatments with 
Table 1. Details of observational cases with different management practices used for model validation.

\begin{tabular}{llcll}
\hline Period & Treatment $^{\mathrm{a}}$ & $\mathrm{N}$ & Variables involved in model validation & Data source \\
\hline Oct 2005-Oct 2006 & CT & 430 & Yield & $(1)$ \\
& IT & 360 & Yield & $(1)$ \\
Oct 2006-Oct 2007 & CT & 430 & Yield & $(1)$ \\
& IT & 360 & Yield & $(1)$ \\
Oct 2007-Oct 2008 & CT & 295 & Yield, $T_{\mathrm{s}}, M_{\mathrm{S}}$ & $(1)$ \\
& IT & 240 & Yield & $(1)$ \\
Oct 2008-Oct 2009 & WS & 390 & Yield, $\mathrm{N}_{2} \mathrm{O}, \mathrm{NO}, \mathrm{NEE}^{\mathrm{b}}, T_{\mathrm{s}}, M_{\mathrm{s}}, \mathrm{AB}$ & $(1),(2),(3)$ \\
& NS & 390 & Yield, $\mathrm{N}_{2} \mathrm{O}, \mathrm{NO}$ & $(1),(2)$, \\
Oct 2009-Oct 2010 & $\mathrm{U}$ & 430 & Yield, $\mathrm{N}_{2} \mathrm{O}, \mathrm{NO}, \mathrm{NEE}^{\mathrm{b}}, T_{\mathrm{s}}, M_{\mathrm{s}} \mathrm{AB}$, & $(2),(4)$ \\
& DCD & 430 & Yield, $\mathrm{N}_{2} \mathrm{O}, \mathrm{NO}$ & $(2),(4)$ \\
& DMPP & 430 & Yield, $\mathrm{N}_{2} \mathrm{O}, \mathrm{NO}$ & $(2),(4)$ \\
& $\mathrm{N} 135$ & 430 & Yield, $\mathrm{N}_{2} \mathrm{O}, \mathrm{NO}, \mathrm{CH}_{4}$ & $(2),(5)$ \\
& $\mathrm{N} 270$ & 430 & Yield, $\mathrm{N}_{2} \mathrm{O}, \mathrm{NO}, \mathrm{CH}_{4}$ & $(2),(5)$ \\
& $\mathrm{N} 430$ & 430 & Yield, $\mathrm{N}_{2} \mathrm{O}, \mathrm{NO}, \mathrm{CH}_{4}$ & $(2),(5)$ \\
& $\mathrm{N} 650$ & 430 & Yield, $\mathrm{N}_{2} \mathrm{O}, \mathrm{NO}, \mathrm{CH}_{4}$ & $(2),(5)$ \\
& N850 & 430 & Yield, $\mathrm{N}_{2} \mathrm{O}, \mathrm{NO}, \mathrm{CH}_{4}$ & $(2),(5)$ \\
\hline
\end{tabular}

\footnotetext{
a Treatment code definitions are found in the text.

b Observations are from April 2009 to April 2010, spanning WS and U treatments.

$\mathrm{N}$, nitrogen fertilizer application rates $\left(\mathrm{kg} \mathrm{N} \mathrm{ha}^{-1} \mathrm{yr}^{-1}\right) ; T_{\mathrm{S}}$, soil temperature; $M_{\mathrm{s}}$, soil moisture; $\mathrm{AB}$, aboveground biomass; (1),

Liu et al. (2011); (2), unpublished data from the authors; (3), Wang et al. (2013); (4), Liu et al. (2013); (5), Liu et al. (2012).
}

nitrification inhibitor (DCD and DMPP), without inhibitor (U) and with different nitrogen addition rates (N135, N270, N430, N650 and N850). The abbreviations U, DCD and DMPP represented urea alone, urea plus dicyandiamide and urea plus 3, 4-dimethyl pyrazole phosphate, respectively. The abbreviations N135, N270, N430, N650 and N850 stood for the nitrogen application rates of 135, 270, 430, 650 and $850 \mathrm{~kg} \mathrm{Nha}^{-1} \mathrm{yr}^{-1}$, respectively. Management practices details (dates of operation, tillage methods, fertilizer types and application methods, water amount and methods of irrigation) for each treatment are presented in the online supplementary material (Table 1S).

To reduce the residual effects of initial conditions, we conducted simulations of the treatments (Table 1) for seven consecutive years from October 2003 to October 2010 and extracted the results during the periods with observations for validation. Management practices for CT treatment from October 2005 to October 2006 were used to implement the simulation for the first two years (October 2003-October 2005) when detailed information of management practice information was unavailable.

\subsection{Management practice scenarios}

To assess the biogeochemical effects of alternative management practices and thereby identify the BMP, model simulations of possible scenarios must be conducted. We designed two groups of management practice scenarios for this purpose (Table 2). One included 12 single-factor scenarios, each of which varied a single management practice while keeping others consistent with the baseline scenario. The other in- cluded two improved scenarios, each of which was set by referring to the results of the single-factor scenarios and simultaneously considering multiple types of management practices. More details about the settings for improved scenarios are given in Sect. 4.3, and the single-factor scenarios are detailed in this section.

With respect to crop residue management, we set no-straw incorporation (NSI) and all-straw incorporation (ASI) scenarios because these two treatments are commonly applied in northern China, with the former being dominant in the past and the latter encouraged by the current policy (Jiang et al., 2012). After harvest, the straws were cut into small pieces and then returned back to the field for the ASI scenario, or removed from the field for the NSI scenario. The operations for the NSI and ASI scenarios other than crop straw management were set by referring to the WS and U treatments (Tables 1 and 1S) and described as follows. The seeding and harvest dates for wheat were 21 October and 3 June, respectively, and those for maize were 6 June and 14 October, respectively. Tillage with a depth of approximately $20 \mathrm{~cm}$ occurs immediately before seeding for each crop. Nitrogen fertilizers are applied at $430 \mathrm{~kg} \mathrm{~N} \mathrm{ha}^{-1}$, with fertilizer type(s) and the application schedule following those of the $\mathrm{U}$ treatment (Tables 1 and 1S). Five times of irrigation (on 22 March, 4 May, 18 June, 8 August, and 18 December) occur annually, with $80 \mathrm{~mm}$ (as the average value of the U treatment) for each time.

We set the ASI as the baseline scenario in this study considering that straw incorporation for the wheat-maize cropping system in northern China has been required recently by policy and that the nitrogen application rate of approximately 
Table 2. Detailed management practices for each scenario.

\begin{tabular}{|c|c|c|c|c|c|}
\hline Scenarios $^{\mathrm{a}}$ & $\mathrm{N}$ & NI & SI & Tillage & Irrigation \\
\hline \multicolumn{6}{|c|}{ Single factor* } \\
\hline ASI & 430 & $x$ & $\sqrt{ }$ & $\sqrt{ }$ & 5 times, $80 \mathrm{~mm}$ for each ${ }^{\mathrm{b}}$ \\
\hline NSI & 430 & $x$ & $x$ & $\sqrt{ }$ & Same as ASI \\
\hline NT & 430 & $x$ & $\sqrt{ }$ & $\times$ & Same as ASI \\
\hline DCDI & 430 & $\sqrt{ }$ & $\sqrt{ }$ & $\sqrt{ }$ & Same as ASI \\
\hline DMPPI & 430 & $\sqrt{ }$ & $\sqrt{ }$ & $\sqrt{ }$ & Same as ASI \\
\hline N301 & 301 & $x$ & $\sqrt{ }$ & $\sqrt{ }$ & Same as ASI \\
\hline N366 & 366 & $x$ & $\sqrt{ }$ & $\sqrt{ }$ & Same as ASI \\
\hline N495 & 495 & $x$ & $\sqrt{ }$ & $\sqrt{ }$ & Same as ASI \\
\hline N559 & 559 & $x$ & $\sqrt{ }$ & $\sqrt{ }$ & Same as ASI \\
\hline IRRindex & 430 & $x$ & $\sqrt{ }$ & $\sqrt{ }$ & Many times ${ }^{\mathrm{c}}$ \\
\hline IRR300 & 430 & $x$ & $\sqrt{ }$ & $\sqrt{ }$ & 5 times, $60 \mathrm{~mm}$ for each ${ }^{\mathrm{b}}$ \\
\hline IRR500 & 430 & $x$ & $\sqrt{ }$ & $\sqrt{ }$ & 5 times, $100 \mathrm{~mm}$ for each ${ }^{b}$ \\
\hline \multicolumn{6}{|l|}{ Improved $^{\#}$} \\
\hline Imp1 & 366 & $x$ & $\sqrt{ }$ & $x$ & Many times ${ }^{\mathrm{c}}$ \\
\hline Imp2 & 366 & $x$ & $\sqrt{ }$ & $\sqrt{ }$ & Same as IRR300 \\
\hline
\end{tabular}

$\mathrm{N}$, nitrogen application rate (unit: $\left.\mathrm{kg} \mathrm{N} \mathrm{ha}^{-1} \mathrm{yr}^{-1}\right)$; NI, nitrification inhibitor ( $\sqrt{ }$ for yes and $\times$ for no); SI, straw incorporation $(\sqrt{ }$ for yes and $\times$ for no); Tillage, $\sqrt{ }$ for yes and $\times$ for no.

$\times$ for no); SI, straw incorporation $(\sqrt{ }$ for yes and $\times$ for no); Tillage, $\sqrt{ }$ for yes and $\times$ for
a The management practices other than those listed in this table were the same for all the scenarios and were described in the text.

${ }^{\mathrm{b}}$ Irrigation occurred on March 22, May 4, June 18, August 8, and December 18 of each year. ${ }^{c}$ Irrigation happened whenever there was a water deficit for the crop demands, with irrigation indexes of 0.3 and 0.25 for IRRindex and Imp1, respectively.

* Single factors of straw management, tillage, inhibitor use, nitrogen dose and irrigation were separately considered to set the scenarios.

\# Multiple factors were considered to set the scenarios for improved management alternatives.

$430 \mathrm{~kg} \mathrm{~N} \mathrm{ha}^{-1} \mathrm{yr}^{-1}$ was commonly adopted by the farmers in the region of our field site (Zhao et al., 2009).

The other single-factor scenarios other than NSI and ASI included NT (no tillage), DCDI and DMPPI (use of nitrification inhibitors), N301, N366, N495 and N559 (different nitrogen addition rates) as well as IRRindex, IRR300 and IRR500 (irrigation). These scenarios were designed by altering one of the ASI management settings at a time. The management setting differences between these scenarios and ASI are listed in Table 2 and briefly described as follows. For NT, crop residues are left at the soil surface with the soil untilled. For DCDI and DMPPI, the nitrification inhibitors dicyandiamide and 3, 4-dimethyl pyrazole phosphate are used with urea, respectively. In comparison to the ASI, the N301 and N366 scenarios receive nitrogen fertilizer applications at $30 \%$ and $15 \%$ lower rates, respectively, while N495 and $\mathrm{N} 559$ at $15 \%$ and $30 \%$ higher rates, respectively. For the IRRindex, irrigation occurs whenever crop growth is limited with the soil water supply, and the amount of irrigation water each time is determined by multiplying the input parameter irrigation index by the deficit of available soil water for plant uptake. In this scenario, the irrigation index was equal to 0.3 to ensure the same annual irrigation amounts as that of ASI (400 $\mathrm{mm} \mathrm{yr}^{-1}$ ). Relative to ASI, the annual irrigation amounts are $25 \%$ lower and higher for IRR300 and IRR500, respectively. To assess the effects of different management practices at the decadal scale, we performed the model simulation for each scenario for $20 \mathrm{yr}$. As this was supposed to represent the actual rainfall situation, we did not con- sider using rainfall data set generated randomly or using extreme weather years. The simulations were driven by actual daily meteorological data at Yuncheng station from 1991 to 2010 (ftp://ftp.ncdc.noaa.gov/pub/data/gsod/). We recorded the annual outputs for grain yields, NEE, SOC content, nitrate leaching, $\mathrm{NH}_{3}$ volatilization and emissions of $\mathrm{CH}_{4}$, $\mathrm{N}_{2} \mathrm{O}$ and $\mathrm{NO}$, thereby calculating the $20 \mathrm{yr}$ averages for individual scenarios. These average values were further used for managerial assessments.

\subsection{Statistics and data analysis}

To quantify the discrepancy between simulated and observed results, the statistical criteria of the root mean square error (RMSE), relative mean deviation (RMD) and model efficiency (ME) were calculated (Loague and Green, 1991; Smith et al., 1997). The RMSE (Eq. 1) was calculated to measure the coincidence between observed and simulated values, while the RMD (Eq. 2) was calculated to evaluate the systematic bias of the model. The ME (Eq. 3) was a measure of the improvement in model predictions relative to the mean of the measurements. A positive ME value indicates that the simulated values would describe the trend in the measured data better than the mean of the observations, while a negative value indicates that the simulated values would describe the data worse than the mean of the observations (Smith et al., 1997; Miehle et al., 2006). The RMSE and RMD equaled 0 and the ME equaled 1 for an ideal fitting (Miehle et al., 2006). In addition, a zero-intercept linear regression between simulations and observations was also used to evaluate model performance. The slope of the linear regression indicates a bias extent. The determination coefficient $\left(R^{2}\right)$ of the linear regression would evaluate how well the simulations match the observed data.

$$
\begin{aligned}
& \mathrm{RMSE}=\frac{100}{\bar{O}} \sqrt{\frac{\sum_{i=1}^{n}\left(P_{i}-O_{i}\right)^{2}}{n}} \\
& \mathrm{RMD}=\frac{100}{\bar{O}} \sum_{i=1}^{n} \frac{P_{i}-O_{i}}{n} \\
& \mathrm{ME}=1-\frac{\sum_{i=1}^{n}\left(P_{i}-O_{i}\right)^{2}}{\sum_{i=1}^{n}\left(O_{i}-\bar{O}\right)^{2}}
\end{aligned}
$$

In Eqs. (1)-(3) $O_{i}$ is the observed (measured) values, $P_{i}$ is the predicted values, $\bar{O}$ and $\bar{P}$ are the mean of the observed and simulated data, respectively, and $n$ is the number of paired values.

\subsection{Methods for identifying the best management practices}

We used two methods to identify the BMP. One is a subjective method by combining the single-factorial practices with 
the maximum benefits (as compared to the baseline scenario) in terms of enhancing crop yields while reducing NEGE, $\mathrm{NH}_{3}$ and $\mathrm{NO}$ emissions and nitrate leaching (Farahbakhshazad et al., 2008). And the other is an objective method we attempt to establish in this study. This objective method uses quantitative criteria in conjunction with given constraints to identify the BMP from scenarios. Assessment index $(I)$ is the quantitative criteria, which is a price-based proxy that is determined by the values of goal variables and the price-based coefficient for each goal variable. It is calculated with the formula of Eq. (4). As the higher $I$ value the better, the BMP should potentially be the scenario with the highest $I$ value. However, as the assessment index only include the effects of goal variables, constraints were also set to help choosing BMP for specific local conditions. Constraints can be a number of limits in light of policies, local resource availability and/or technical feasibility.

$$
\begin{aligned}
I & =\sum_{i=1}^{n}\left(a_{i} \cdot P_{i}\right)-b \cdot \mathrm{NEGE}-c \cdot \mathrm{NH}_{3}-d \cdot \mathrm{NL} \\
& -e \cdot \mathrm{NO}-f \cdot \mathrm{N}_{2} \mathrm{O}_{(\mathrm{ODM})}
\end{aligned}
$$

In Eq. (4), $I$ (unit: $\$ \mathrm{ha}^{-1}$ ) is an index regarded as a measure of the comprehensive effects of productivity $(P)$, NEGE, $\mathrm{NH}_{3}$ volatilization, nitrate leaching (NL), NO release and emission of $\mathrm{N}_{2} \mathrm{O}_{(\text {ODM) }}$ as an ozone layer depletion matter. The productivity item was specified to wheat yield $\left(P_{1}\right)$ and maize yield $\left(P_{2}\right)$, with $n=2$, for our case of winter wheatsummer maize cropping system. The coefficients $a, b, c, d$, $e$ and $f$ are price-based proxies of $P$, NEGE, $\mathrm{NH}_{3}, \mathrm{NL}$, $\mathrm{NO}$ and $\mathrm{N}_{2} \mathrm{O}_{(\mathrm{ODE})}$, respectively. The values of $a_{1}$ and $a_{2}$ are set as USD $891 \mathrm{Mg}^{-1} \mathrm{C}$ (http://www.czce.com.cn/portal/ index.htm) and USD $938 \mathrm{Mg}^{-1} \mathrm{C}$ (http://www.pvc123.com/ b-daliantrade/), respectively, by referring to the recent market prices. The $b$ value is set as USD $7.00 \mathrm{Mg}^{-1} \mathrm{CO}_{2}$-eq by referring to the recent price of the carbon trade market (https: $/ /$ www.theice.com/ccx.jhtml). The coefficients $c, d, e$ and $f$ are determined according to the costs of N-related impacts or mitigation, with values of USD $5.02 \mathrm{~kg}^{-1} \mathrm{~N}$ (Birch et al., 2011), USD $1.92 \mathrm{~kg}^{-1} \mathrm{~N}$ (Dodds et al., 2009; van Grinsven et al., 2010; Compton et al., 2011), USD $25.78 \mathrm{~kg}^{-1} \mathrm{~N}$ (Birch et al. 2011) and USD $1.33 \mathrm{~kg}^{-1} \mathrm{~N}$ (Compton et al., 2011), respectively.

\section{Results}

\subsection{Model validation}

\subsubsection{Soil temperature and moisture}

Figure 1a shows the predictions and observations of daily mean soil $(5 \mathrm{~cm})$ temperature from October 2007 to October 2010. The temporal pattern and magnitudes of the modeled values were in agreement with the observations.
The zero-intercept linear regression of simulated against observed daily mean soil temperatures yielded an $R^{2}$ of 0.97 and a slope of $1.00(n=1045, P<0.01)$. Values of RMSE, RMD and ME were $10.13 \% \mathrm{~m} 1.30 \%$ and 0.98 , respectively (Table 3).

As Fig. 1b shows, the model prediction generally captured the temporal variation and magnitude of the measured soil $(0-6 \mathrm{~cm})$ moisture (WFPS, i.e., water-filled pore space) most of the time, although discrepancy existed on some values. The zero-intercept linear regression of simulated vs. observed daily mean soil moisture showed an $R^{2}$ of 0.29 and a slope of $1.04(n=877, P<0.01)$. The RMSE, RMD and ME were calculated as $34.57 \%, 68.17 \%$ and 0.05 (Table 3).

\subsubsection{Aboveground biomass dynamics and grain yield}

The simulated dynamic aboveground biomass for wheat and maize were generally close to the field observations (Fig. 2a). As the observations show, the aboveground biomass of winter wheat was quite low in winter and began to increase dramatically after reviving in the spring. The model successfully simulated this dynamic. The zero-intercept linear regression of simulated aboveground biomass against the observations yielded an $R^{2}$ of 0.92 and a slope of $1.06(n=72, P<0.01$; Table 3), indicating a good agreement. The simulation resulted in RMSE, RMD and ME values of $28.81 \%, 13.00 \%$ and 0.92 , respectively (Table 3 ).

Figure $2 b$ compares the simulated and observed yields of wheat and maize in all treatments from October 2005 to October 2010 (data are presented in Table 2S). As the zerointercept linear regression illustrates, there was a good agreement between simulations and observations of the yields, with a slope of 0.96 and $R^{2}$ of $0.65(n=32, P<0.01$, Table 3). Values of RMSE, RMD and ME were $9.51 \%$, $-2.76 \%$ and 0.70 , respectively (Table 3 ). As the observations demonstrated, crop yields did not significantly increase in response to further application rates of nitrogen fertilizers above a certain level (Liu et al., 2012; Table 2S). This feature was properly reflected by the model simulation as well (Table $2 \mathrm{~S}$ ), which confirmed the ability of the model to simulate the effects of fertilizer nitrogen addition on crop yields.

\subsubsection{Net ecosystem exchange of carbon dioxide}

Figure 3a displays simulated and observed daily NEE fluxes. These data suggest that the model generally captured seasonal fluctuations of the NEE fluxes in the involved wheatmaize rotation. In general, negative NEE fluxes were observed from March to May and July to September when the cops were growing quickly. However, on cloudy or rainy days, the abrupt increases of NEE fluxes up to above zero were not well reflected by the model. Nevertheless, a zerointercept linear relationship between the simulated $(S)$ and observed $(O)$ daily NEE fluxes was found $\left(S=0.91 O, R^{2}=\right.$ $0.55, n=365, P<0.01$; Table 3 ). The simulation gave an 
Table 3. Statistics of DNDC simulations versus observations with regards to concerned variables.

\begin{tabular}{|c|c|c|c|c|c|c|c|c|}
\hline \multirow[b]{2}{*}{ Concerned variables } & \multicolumn{4}{|c|}{ Linear regression } & \multirow{2}{*}{$\begin{array}{r}\text { RMSE } \\
(\%)\end{array}$} & \multirow{2}{*}{$\begin{array}{r}\text { RMD } \\
(\%)\end{array}$} & \multirow[b]{2}{*}{ ME } & \multirow[b]{2}{*}{$n$} \\
\hline & Intercept & Slope & $R^{2}$ & $P$ & & & & \\
\hline Soil temperature ${ }^{\mathrm{a}}$ & 0 & 1.00 & 0.97 & $<0.01$ & 10.13 & 1.30 & 0.98 & 1045 \\
\hline Soil moisture ${ }^{b}$ & 0 & 1.04 & 0.29 & $<0.01$ & 34.57 & 8.17 & 0.05 & 877 \\
\hline Aboveground biomass ${ }^{c}$ & 0 & 1.06 & 0.92 & $<0.01$ & 28.81 & 13.00 & 0.92 & 72 \\
\hline Yield $^{\mathrm{c}}$ & 0 & 0.96 & 0.65 & $<0.01$ & 9.51 & -2.76 & 0.70 & 32 \\
\hline Daily $\mathrm{NEE}^{\mathrm{d}}$ & 0 & 0.92 & 0.58 & $<0.01$ & - & - & 0.40 & 365 \\
\hline Daily $\mathrm{NH}_{3}$ volatilization ${ }^{\mathrm{e}}$ & 0 & 1.22 & 0.77 & $<0.01$ & 77.73 & 4.17 & 0.21 & 11 \\
\hline Annual $\mathrm{N}_{2} \mathrm{O}$ emission ${ }^{\mathrm{f}}$ & 0 & 1.09 & 0.78 & $<0.01$ & 19.45 & 8.74 & 0.57 & 10 \\
\hline Annual NO emission ${ }^{\mathrm{f}}$ & 0 & 1.07 & 0.88 & $<0.01$ & 27.45 & 0.32 & 0.53 & 10 \\
\hline
\end{tabular}

${ }^{\mathrm{a}}{ }^{\circ} \mathrm{C} ;{ }^{\mathrm{b}}$, WFPS; ${ }^{\mathrm{c}} \mathrm{MgCha}^{-1} ;{ }^{\mathrm{d}} \mathrm{kg} \mathrm{Cha}^{-1} \mathrm{~d}^{-1} ;{ }^{\mathrm{e}} \mathrm{kg} \mathrm{Nha}^{-1} \mathrm{~d}^{-1} ;{ }^{\mathrm{f}} \mathrm{kg} \mathrm{Nha}^{-1} \mathrm{yr}^{-1} ;-$ not calculated.
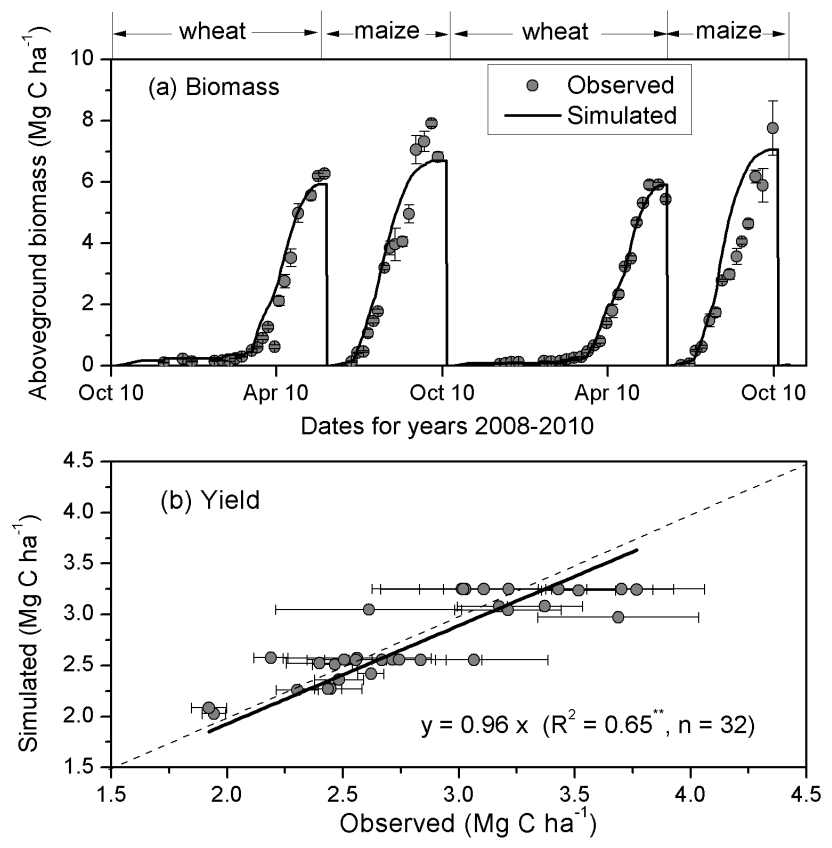

Fig. 2. Simulated and observed aboveground biomass (a) and grain yields (b) of the wheat-maize rotations. Aboveground biomass of wheat-maize rotation was for the WS treatment in 2008-2009 and the $U$ treatment in 2009-2010, with the vertical bars indicating the standard errors of 3 replicates (unpublished data of the authors, which were weekly measured since winter reviving or summer maize germination using the method described by Liu et al., 2011, 2012). Grain yields of individual crop season for all treatments described in Table 1, with horizontal bars indicating the standard errors of 3 replicates, were cited from Liu et al. (2011, 2012, 2013). ${ }^{* *}$ indicates a significance level of $P<0.01$.

ME of $4.28 \%$ and 0.36 (Table 3). We did not calculate the RMSE and RMD here because the criteria did not apply to our NEE data with a small mean value of observation due to frequent positive and negative fluxes.

Although the cumulative NEE resulting from the model simulation and observations were periodically inconsis-

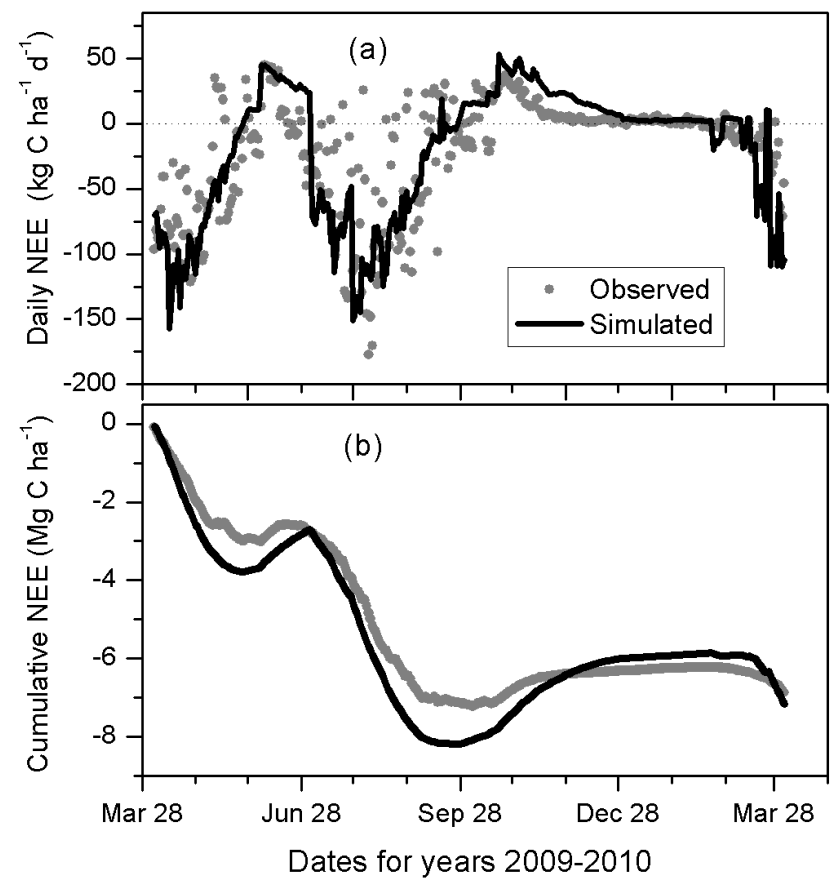

Fig. 3. Observed and simulated daily (a) and cumulative (b) net ecosystem exchange of carbon dioxide (NEE) in the wheat-maize rotation during 2009-2010. The observed data during the non-maize period were cited from Wang et al. (2013) and those during the maize growing period were unpublished data from the authors, which were measured with the eddy covariance technique as described by Wang et al. (2013).

tent with each other (Fig. 3b), their values over the year-round period (365 days) were very close $(-7.16$ and $-6.86 \mathrm{Mg} \mathrm{Cha}^{-1} \mathrm{yr}^{-1}$, respectively, with a difference of approximately of $4 \%$ of the observation).

\subsubsection{Ammonia volatilization}

We plotted the simulated and observed daily and cumulative $\mathrm{NH}_{3}$ volatilization in Fig. 4. As the figure demonstrates, 


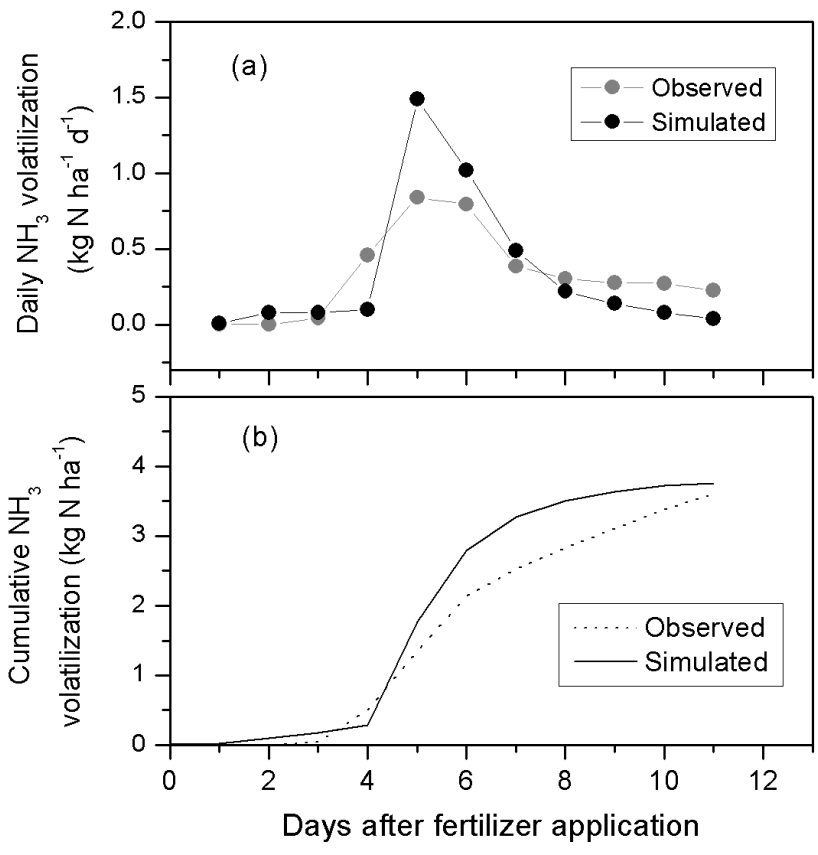

Fig. 4. Observed and simulated daily (a) and cumulative (b) ammonium volatilization due to one fertilizer application event in the wheat-maize field during July of 2008. The Observed data were adapted from Yang et al. (2011).

the temporal variation pattern given by the simulated fluxes generally followed that of the observed fluxes, though the model simulation overestimated the peak flux on the fifth day after fertilizer amendment and slightly underestimated the fluxes on the last three days. Despite these differences, the model simulation yielded a cumulative $\mathrm{NH}_{3}$ emission of $3.76 \mathrm{~kg} \mathrm{Nha}^{-1}$ as a consequence of the fertilization event, which was approximately $4 \%$ higher than the observed value (3.60 $\mathrm{kg} \mathrm{N} \mathrm{ha}^{-1}$ ). The zero-intercept regression of simulated vs. observed daily $\mathrm{NH}_{3}$ volatilization yielded an $R^{2}$ of 0.77 and a slope of $1.22(n=11, P<0.01)$. The simulation resulted in RMSE, RMD and ME values of $77.73 \%, 4.17 \%$ and 0.21 , respectively (Table 3 ).

\subsubsection{Methane emission}

Figure 5a illustrates the simulated and observed daily $\mathrm{CH}_{4}$ fluxes from October 2009 to October 2010 for the N430 treatment. Similar results for the other treatments were also obtained (data not shown). As shown in Fig. 5a, the observed $\mathrm{CH}_{4}$ fluxes were generally negative, with stronger fluxes during the period from May to July than those during other periods. The model successfully simulated this temporal pattern, although the simulated values were slightly lower than the observed ones in the last two months. The simulated annual amounts of net $\mathrm{CH}_{4}$ emission showed no significant response to the different fertilizer application rates (Fig. 5b), which
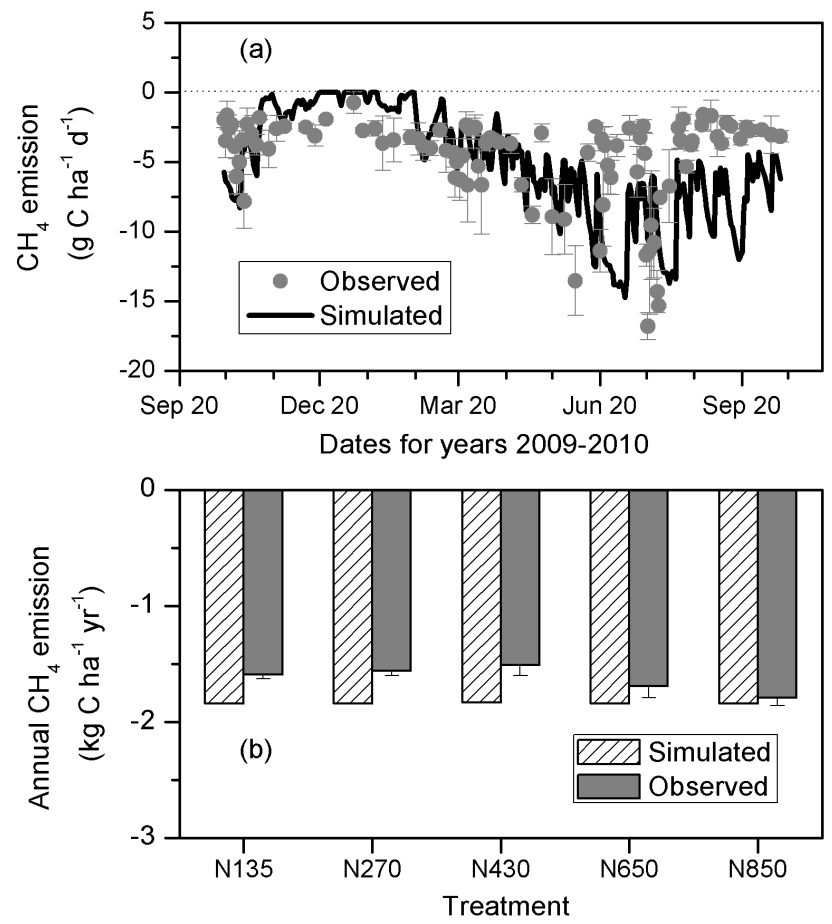

Fig. 5. Observed and simulated daily methane $\left(\mathrm{CH}_{4}\right)$ fluxes for treatment $\mathrm{N} 430$ (a), and cumulative $\mathrm{CH}_{4}$ emissions (b) for treatments N135, N270, N430, N650 and N850 from 2009 to 2010. Treatment code definitions can be found in Table 1 and in the text. The observed data were adapted from Liu et al. (2012).

was consistent with the experimental results reported by Liu et al. (2012).

\subsubsection{Nitrous oxide and nitric oxide}

Figure $6 \mathrm{a}$ and $\mathrm{b}$ illustrates the simulated and observed daily $\mathrm{N}_{2} \mathrm{O}$ fluxes from October 2008 to October 2009 for the WS and NS treatments (the simulated and observed fluxes of $\mathrm{N}_{2} \mathrm{O}$ during October 2009 to October 2010 for other treatments were available but not shown here). The observed daily $\mathrm{N}_{2} \mathrm{O}$ fluxes were highly variable within each year. High peaks usually appeared following fertilization, irrigation (especially those occurred after fertilizer application) and heavy rainfall. Compared with the observed fluxes, the DNDC model generally captured the temporal pattern of daily $\mathrm{N}_{2} \mathrm{O}$ emissions, although discrepancies existed in the magnitudes of some peak emissions (e.g., the model underestimated $\mathrm{N}_{2} \mathrm{O}$ fluxes caused by irrigation following fertilization in July 2009 for both treatments).

Of the 10 involved treatments with different management practices (Table 1), the observed annual $\mathrm{N}_{2} \mathrm{O}$ emissions ranged from 2.09 to $5.57 \mathrm{~kg} \mathrm{Nha}^{-1}$, with an average of $3.70 \mathrm{~kg} \mathrm{~N} \mathrm{ha}^{-1}$ (Fig. 6c). In consonance with observations, the model simulations for these treatments resulted in annual $\mathrm{N}_{2} \mathrm{O}$ emissions of 2.67 to $6.95 \mathrm{~kg} \mathrm{Nha}^{-1}$, with an average 

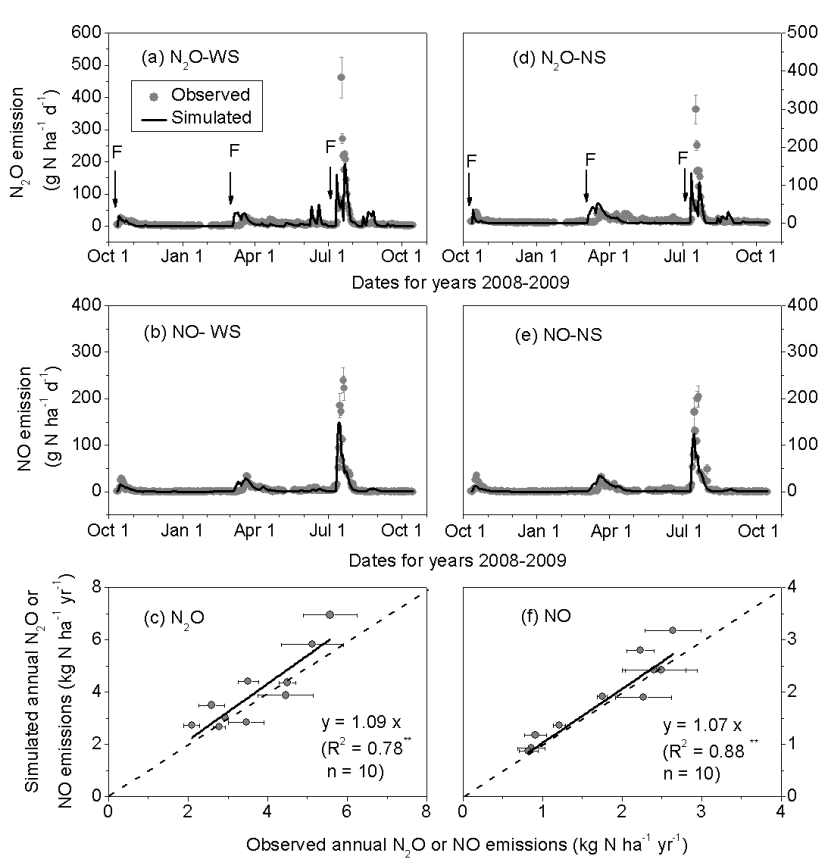

Fig. 6. Observed and simulated daily fluxes of $\mathrm{N}_{2} \mathrm{O}$ and $\mathrm{NO}$ from the WS (a, b) and NS (d, e) treatments in 2008-2009, comparison of the observed and simulated annually cumulative $\mathrm{N}_{2} \mathrm{O}$ (c) and $\mathrm{NO}$ (f) emissions from the wheat-maize rotations with different management practices. The arrows with capital letter $F$ indicate the fertilization time. Error bars indicate the standard errors of 3 replicates. ** indicates a significance level of $P<0.01$. The observed data for $\mathrm{N}_{2} \mathrm{O}$ and daily fluxes of $\mathrm{NO}$ (b and $\mathbf{e}$ ) were adapted from Liu et al. $(2011,2012,2013)$ and remaining data for annual NO emission (f) were unpublished data of the authors, which were measured with the same method described by Liu et al. (2011).

value of $4.02 \mathrm{~kg} \mathrm{Nha}^{-1}$. Comparison between the computed and observed annual $\mathrm{N}_{2} \mathrm{O}$ emissions across different treatments yielded an $R^{2}$ of 0.78 and a slope of 1.09 for a significant zero-intercept linear regression $(n=10, P<0.01$; Table 3). The model simulation resulted in RMSE, RMD and $\mathrm{ME}$ values of $19.45 \%, 8.74 \%$ and 0.57 , respectively, in terms of annual $\mathrm{N}_{2} \mathrm{O}$ emission (Table 3 ).

Figure $6 \mathrm{~d}$ and e shows the simulated and observed daily NO fluxes from WS and NS treatments from October 2008 to October 2009. The simulated and observed fluxes of NO for other treatments from October 2009 to October 2010 were also available but not shown here. The observed daily NO fluxes remained stable at a low level most of the time and were obviously higher during the three periods following fertilization events. The model well captured the temporal pattern and magnitudes of NO fluxes.

With regards to the annual NO emissions from the 10 involved treatments under different management practices (Table 1), the observed and simulated values were statistically comparable (Fig. 6f). The observed values ranged from 0.82 to $2.64 \mathrm{~kg} \mathrm{~N} \mathrm{ha}^{-1}$, with an average of $1.76 \mathrm{~kg} \mathrm{~N} \mathrm{ha}^{-1}$, while the simulated values ranged from 0.88 to $3.18 \mathrm{~kg} \mathrm{Nha}^{-1}$, with an average of $1.96 \mathrm{~kg} \mathrm{Nha}^{-1}$. A zero-intercept linear regression between the simulated and observed annual NO emissions yielded an $R^{2}$ of 0.88 and a slope of $1.07(n=10$, $P<0.01$, Table 3). The values of RMSE, RMD and ME were $27.45 \%, 0.32 \%$ and 0.53 , respectively (Table 3 ).

As the above results demonstrate, the simulated and observed annual $\mathrm{N}_{2} \mathrm{O}$ and $\mathrm{NO}$ emissions showed consistency in spite of the wide range of management practices (Fig. 6c and $\mathrm{f}$ ). This indicates that the model simulation was able to reflect the effects of different management practices on the emission of both gases. In particular, the stimulatory effects of wheat straw incorporation on the cumulative $\mathrm{N}_{2} \mathrm{O}$ and $\mathrm{NO}$ emissions in the following maize season were well simulated by the model (Fig. 6a-b and d-e). Following the previous study that proved the ability of the model to simulate the effects of nitrification inhibitor dicyandiamide on $\mathrm{N}_{2} \mathrm{O}$ emission from urine-amended pasture (Giltrap et al., 2010b), our results further proved the model's ability to simulate the $\mathrm{N}_{2} \mathrm{O}$ and $\mathrm{NO}$ emissions which were significantly inhibited by either dicyandiamide or 3, 4-dimethyl pyrazole phosphate $(P<0.01)$ from the wheat-maize cropland.

\subsection{Biogeochemical effects of single-factor management practices}

The results of goal variables from consecutive simulations over $20 \mathrm{yr}$ for the ASI and NSI scenarios are displayed in Fig. 7 (results for the other scenarios were available but not shown). The annual averages of individual goal variables resulting from the $20 \mathrm{yr}$ simulations are presented in Fig. 8 for all scenarios listed in Table 2.

As Figs. 7a, b and 8a illustrate, the modeled results showed that straw incorporation could slightly increase grain yields of both crops as compared to the no-straw incorporation practice (wheat: 2.28 versus $2.24 \mathrm{Mg} \mathrm{Cha}^{-1}$ on average; maize: 3.14 versus $3.06 \mathrm{MgC} \mathrm{ha}^{-1}$ on average). The $\Delta \mathrm{SOC}$ values of NSI were near zero, indicating a relatively stable SOC content. Meanwhile, the $\triangle$ SOC values of ASI were always positive over $20 \mathrm{yr}$, implying an increase in carbon sink (Figs. 7c and 8b). The annual amounts of nitrate leaching for the ASI scenario were higher than those for the NSI scenario in the thirteenth and seventeenth year, while no obvious difference between the two scenarios in other years (Fig. 7d). As a result, the annual average of the ASI was higher than that of NSI (59 versus $43 \mathrm{~kg} \mathrm{Nha}^{-1} \mathrm{yr}^{-1}$ on average). The straw incorporation seemed to greatly enhance $\mathrm{CH}_{4}$ uptake, with annual averages of 2.27 and $1.01 \mathrm{~kg} \mathrm{C} \mathrm{ha}^{-1} \mathrm{yr}^{-1}$ for ASI and NSI, respectively (Figs. $7 \mathrm{f}$ and $8 \mathrm{~d}$ ). The $\mathrm{N}_{2} \mathrm{O}$ and $\mathrm{NO}$ emissions of ASI were consistently higher than those of NSI (Fig. $7 \mathrm{~g}$ and $\mathrm{h}$ ), with annual averages of 4.41 versus $2.45 \mathrm{~kg} \mathrm{Nha}^{-1} \mathrm{yr}^{-1}$ for $\mathrm{N}_{2} \mathrm{O}$ and 1.95 and $1.38 \mathrm{~kg} \mathrm{Nha}^{-1}$ $\mathrm{yr}^{-1}$ for NO (Fig. 8d). Meanwhile, the annual emissions of both gases for either scenario showed large inter-annual variations (Fig. $7 \mathrm{~g}$ and $\mathrm{h}$ ), with coefficient of variation of 


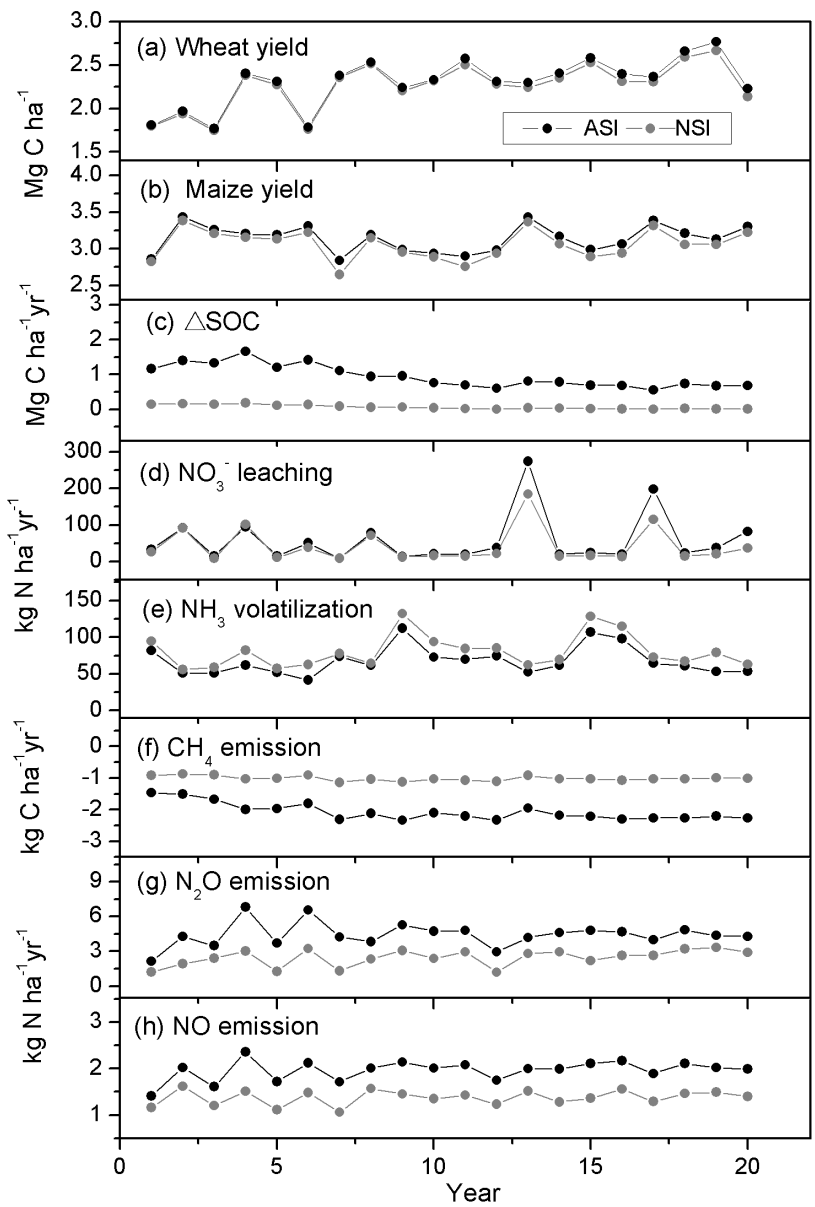

Fig. 7. Modeled yields of wheat and maize, soil organic carbon change $(\triangle \mathrm{SOC})$, nitrate $\left(\mathrm{NO}_{3}^{-}\right)$leaching, ammonia $\left(\mathrm{NH}_{3}\right)$ volatilization, emissions of nitrous oxide $\left(\mathrm{N}_{2} \mathrm{O}\right)$ and nitric oxide (NO) over a 20-year period for the scenarios with all straw incorporation (ASI) and no straw incorporation (NSI). The simulation was driven by the observed daily temperature (maximum and minimum) and precipitation from 1991-2010.

$24-29 \%$ and $11-12 \%$ for $\mathrm{N}_{2} \mathrm{O}$ and $\mathrm{NO}$, respectively. The annual NEGE was positive $\left(0.87 \mathrm{MgCO}_{2}\right.$-eq ha $\left.{ }^{-1} \mathrm{yr}^{-1}\right)$ for the NSI scenario but negative $\left(-1.47 \mathrm{MgCO}_{2}\right.$-eq ha $\left.{ }^{-1} \mathrm{yr}^{-1}\right)$ for the ASI scenario (Fig. 8e).

As Fig. 8a-c and e show, no-till practice (the NT scenario) slightly increased grain yields $(2-3 \%)$ and enlarge $\triangle \mathrm{SOC}(15 \%)$ while reducing $\mathrm{NH}_{3}$ volatilization $(-24 \%)$ and NEGE $(-40 \%)$ in comparison to the ASI scenario. Meanwhile, the NT scenario showed no obvious effects on nitrate leaching or NO emission.

In comparison with the baseline scenario (ASI) in which urea was alone as a nitrogen fertilizer, as Fig. 8a and ce demonstrate, use of nitrification inhibitors (DCDI and DMPPI) did not affect the wheat and maize yields, and decreased nitrate leaching ( $-48 \%$ and $-64 \%$, respectively), emissions of $\mathrm{N}_{2} \mathrm{O}$ ( -24 and $-28 \%$, respectively) and $\mathrm{NO}$

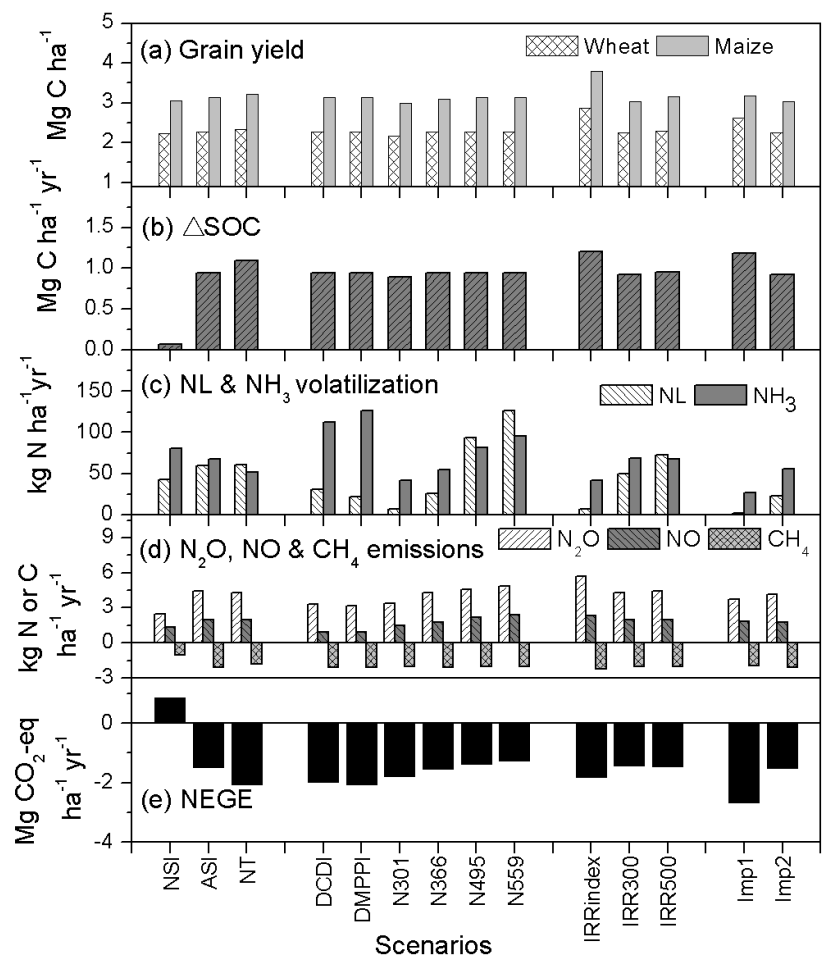

Fig. 8. Averages of the crop yields, soil organic carbon change (SOC), nitrate leaching (NL), ammonia $\left(\mathrm{NH}_{3}\right)$ volatilization, emissions of nitrous oxide $\left(\mathrm{N}_{2} \mathrm{O}\right)$, nitric oxide $(\mathrm{NO})$ and methane $\left(\mathrm{CH}_{4}\right)$, and net emission of greenhouse gases in the ecosystem (NEGE) simulated over a $20 \mathrm{yr}$ period for different management scenarios. The definitions of each scenario can be found in Table 2. NEGE is defined as $\mathrm{CH}_{4}+\mathrm{N}_{2} \mathrm{O}-\mathrm{SOC}$ and expressed as a $\mathrm{CO}_{2}$ equivalent based on the $100 \mathrm{yr}$ global warming potentials, i.e., 25 for $\mathrm{CH}_{4}$ and 298 for $\mathrm{N}_{2} \mathrm{O}$ (IPCC, 2007).

$(-51 \%$ and $-52 \%$, respectively), and the NEGE ( -34 and $-40 \%$, respectively), but greatly stimulated $\mathrm{NH}_{3}$ volatilization (66 and $86 \%$, respectively). According the results in Fig. 8c, the fertilizer nitrogen loss rates due to $\mathrm{NH}_{3}$ volatilization were 16,26 and $29 \%$, for the ASI, DCDI and DMPPI scenarios, respectively.

Reducing the nitrogen addition rate from 430 (ASI) to 366 (N366) $\mathrm{kg} \mathrm{N} \mathrm{ha}^{-1} \mathrm{yr}^{-1}$ had no obvious effects on crop yield (reduction of $0.05-1 \%$ ). When the nitrogen addition rate was further decreased to $301 \mathrm{~kg} \mathrm{~N} \mathrm{ha}^{-1} \mathrm{yr}^{-1}$ (N301), grain yields were decreased $(-5 \%)$. Increasing the nitrogen addition rate to 495 (N495) or 559 (N559) $\mathrm{kg} \mathrm{N} \mathrm{ha}^{-1} \mathrm{yr}^{-1}$ did not further increase wheat or maize yield any more, as compared to the ASI scenario (Fig. 8a). The annual $\triangle \mathrm{SOC}$ of scenarios with different nitrogen application rates (ASI, N301, N366, N495 and N559) showed no obvious differences from each other. However, the NEGE and nitrogen losses via $\mathrm{NH}_{3}$ volatilization, nitrate leaching and NO emission increased with the increase of nitrogen addition rate (Fig. 8c-e). 
Changing the irrigation method adopted in the ASI to that based on irrigation index (IRRindex) increased the wheat and maize yields to a large extent ( 26 and $21 \%$, respectively). When compared with ASI, the IRRindex scenario greatly enhanced $\triangle \mathrm{SOC}(27 \%)$ while greatly reducing the nitrogen losses via $\mathrm{NH}_{3}$ volatilization and nitrate leaching $(-39$ and $-89 \%$, respectively). However, it also stimulated $\mathrm{N}_{2} \mathrm{O}$ and NO emissions (30 and $19 \%$, respectively). Nevertheless, the increase in $\triangle \mathrm{SOC}$ offset the increase in $\mathrm{N}_{2} \mathrm{O}$ emission, thereby reducing the NEGE by $23 \%$. An increase (IRR500) or decrease (IRR300) in water amounts for individual irrigation events relative to those of ASI showed no obvious effects on the crop yield, $\triangle \mathrm{SOC}, \mathrm{NH}_{3}$ volatilization, or emissions of $\mathrm{N}_{2} \mathrm{O}$ and $\mathrm{NO}$, while increasing (22\%) or decreasing $(-17 \%)$ the nitrate leaching.

\subsection{The best management practice}

In order to achieve the BMP scenario with the subjective method adopted by Farahbakhshazad et al. (2008), we summarized the results of single-factor scenarios and determined the following impacts: changing no straw incorporation to straw incorporation practice significantly decreased NEGE; shifting till to no-till practice benefits crop yield and NEGE; reducing nitrogen fertilizer use by $15 \%$ or irrigation water by $25 \%$ did not decrease crop yields while benefiting other goal variables; splitting irrigation into more times based on crop demand increased crop yield, decreased nitrate leaching, $\mathrm{NH}_{3}$ volatilization and NEGE. We composed a new improved management scenario (Imp1) by combining the practices described above. Details of management practices are shown in Table 2. In comparison to the baseline scenario (ASI), results show that the Imp1 scenario significantly decreased the NEGE $(-82 \%)$, nitrate leaching $(-96 \%)$ and $\mathrm{NH}_{3}$ volatilization (-61\%) while slightly increased NO emission (6\%, Figs. 8c-e). At the same time, the wheat and maize yields were increased by 16 and $2 \%$, respectively (Fig. 8a). As the Imp1 is obtained according to the method described by Farahbakhshazad et al. (2008) and results showed significant benefits on environment and crop yields, it can be regarded as BMP. However, the Imp1 will not be widely applicable in the near future, because no-till practice requires extra money on seeding equipment and the frequent irrigation according to crop demands is still impractical due to technical difficulties in northern China. Accordingly, we substituted management practices of no-till and irrigation based on crop demand from Imp1 scenario with deep tillage and regular irrigation based on fixed times, and thereby obtained another improved alternative management scenario (Imp2, Table 2). As Fig. 8 shows, in comparison to the ASI scenario, the Imp2 scenario decreased the NEGE $(-3 \%)$, nitrate leaching $(-62 \%), \mathrm{NH}_{3}$ volatilization $(-18 \%)$ and $\mathrm{NO}$ emission $(-6 \%)$. Meanwhile, the crop yields were sustained while less nitrogen and irrigation were used. Although the comprehensive benefits of Imp2 system were not as good as those of Imp1 system, the benefits were still obvious. Therefore, the Imp1 can be recommended as potential BMP which showed us a direction on future management practices, while Imp1 can be recommended as the practical BMP which can be adopted nowadays for a wheat-maize rotation field at the study region.

We also exemplified application of this newly established method, using all the single-factor and the improved scenarios described above and their simulated annual values (20year averages) of goal variables including grain yield, NEGE, $\mathrm{NH}_{3}$ volatilization, $\mathrm{NO}$ emission and nitrate leaching. Table 4 lists the values of the goal variables and $I$ for individual scenario. The $I$ values varied from USD 4196 to $5833 \mathrm{ha}^{-1}$ (Table 4). The IRRindex scenario obtained the highest $I$ value; while the N559 scenario obtained the lowest $I$ value. According to local conditions, the order of constraints we considered in our case was technical feasibility, yield reduction tolerance $(5 \%)$ and decrease of water and nitrogen fertilizer use. Considering primary constraint, IRRindex, Imp1 and NT with the topmost $I$ values cannot be chosen as BMP nowadays due to technical difficulties of irrigation based on crop demand and tillage in the region. Regarding the constraint of less irrigation water relative to the baseline scenario (ASI), we rejected N366 as the BMP though it has the highest $I$ value excluding IRRindex, Imp1 and NT. Then we came to the scenario Imp2 according to the sequence of I value. Imp2 scenario meets all the constraints and thus be chosen as BMP.

The practices for the Imp2 were designed to use the current crop cultivars, follow the present schedules of planting/harvest, tillage and irrigation, incorporate residues fully at harvest, adopt the sprinkler irrigation with the $25 \%$ reduction of current irrigation water amount, apply urea alone at a $15 \%$ lower rate than the current operation and exclude nitrification inhibitors (Tables 2 and 2S, Sect. 2.4).

\section{Discussion}

\subsection{Model performance}

The DNDC model has been widely tested and applied to the agricultural systems of many countries, and it is based on validation with observations of limited variables (Giltrap et al., 2010a). However, there have been very few reports to validate this process-oriented model with simultaneously measured data of soil environments and multiple goal variables so far with the intention of developing BMP (Farahbakhshazad et al., 2008). In this study, before we attempted to identify the BMPs via model simulation, we made a more complete validation by using the measurements at the same wheat-maize cropping site on soil temperature and moisture, crop growth and yields and fluxes of NEE, $\mathrm{NH}_{3}, \mathrm{CH}_{4}$, $\mathrm{N}_{2} \mathrm{O}$ and $\mathrm{NO}$ under different field management treatments. Our validation results indicate that the model performed well in simulating the soil environments and the multiple goal 
Table 4. Modeled goal variables (annual averages over $20 \mathrm{yr}$ simulation) and values of assessment index $(I)$ for each management practice scenario.

\begin{tabular}{lccrrrrrr}
\hline Scenarios & WY & MY & NEGE & $\mathrm{NH}_{3}$ & $\mathrm{NO}$ & $\mathrm{NL}$ & $\mathrm{N}_{2} \mathrm{O}$ & $I$ \\
\hline IRRindex & 2.87 & 3.79 & -1.81 & 41 & 2.31 & 7 & 5.73 & 5833 \\
Imp1 & 2.62 & 3.19 & -2.68 & 26 & 1.83 & 2 & 3.71 & 5150 \\
NT & 2.33 & 3.23 & -2.06 & 51 & 1.95 & 60 & 4.33 & 4687 \\
N366 & 2.28 & 3.11 & -1.53 & 55 & 1.78 & 26 & 4.27 & 4582 \\
Imp2 & 2.26 & 3.03 & -1.52 & 56 & 1.75 & 22 & 4.13 & 4496 \\
N301 & 2.16 & 2.99 & -1.78 & 41 & 1.50 & 7 & 3.36 & 4484 \\
ASI & 2.28 & 3.14 & -1.47 & 68 & 1.95 & 59 & 4.41 & 4476 \\
IRR500 & 2.29 & 3.16 & -1.46 & 68 & 1.97 & 72 & 4.47 & 4474 \\
IRR300 & 2.26 & 3.04 & -1.43 & 69 & 1.94 & 49 & 4.30 & 4377 \\
DCD & 2.28 & 3.14 & -1.98 & 113 & 0.95 & 30 & 3.33 & 4337 \\
N459 & 2.28 & 3.14 & -1.39 & 82 & 2.17 & 93 & 4.58 & 4335 \\
NSI & 2.24 & 3.06 & 0.87 & 80 & 1.38 & 43 & 2.45 & 4333 \\
DMPP & 2.28 & 3.13 & -2.06 & 126 & 0.93 & 21 & 3.14 & 4278 \\
N559 & 2.28 & 3.14 & -1.27 & 95 & 2.39 & 126 & 4.83 & 4196 \\
\hline
\end{tabular}

WY, Wheat yield $\left(\mathrm{Mg} \mathrm{Cha}^{-1} \mathrm{yr}^{-1}\right)$; MY, Maize yield $\left(\mathrm{MgCha}^{-1} \mathrm{yr}^{-1}\right)$; NEGE, net emission of greenhouse gases in the ecosystem $\left(\mathrm{Mg} \mathrm{CO}_{2}\right.$-eq ha $\left.{ }^{-1} \mathrm{yr}^{-1}\right) ; \mathrm{NH}_{3}, \mathrm{NO}, \mathrm{N}_{2} \mathrm{O}$ and $\mathrm{NL}$, ammonia volatilization, nitric oxide emission, nitrous oxide emission and nitrate leaching, respectively $\left(\mathrm{kg} \mathrm{Nha}^{-1} \mathrm{yr}^{-1}\right)$. I values $\left(\$ \mathrm{ha}^{-1}\right)$ were calculated using Eq. (4) in the text. The description of each scenario can be found in Table 2 and in the text.

variables, although it still showed a few discrepancies on a daily basis. For instance, the abrupt increases of NEE fluxes up to above zero were not well simulated by the model on cloudy or rainy days (Fig. 3). This was caused by the NEE calculation principle of the model, in which a daily NEE flux was determined as the difference between soil heterotrophic respiration and net primary productivity, i.e., the daily plant growth. In this model, the daily plant growth was mainly driven by the accumulated temperature, which did not reflect the reduction of photosynthesis that was induced by the reduction of radiation during cloudy and rainy conditions. Nevertheless, the total simulated $\mathrm{NEE}\left(-7.16 \mathrm{Mg} \mathrm{Cha}^{-1}\right)$ approached the observed value $\left(-6.86 \mathrm{MgC} \mathrm{ha}^{-1}\right)$ over the entire observational period (Fig. 3b). We also compared the modeled conversion coefficient of input carbon with other studies and obtained satisfactory results. Conversion coefficient is defined at the annual scale as a ratio of $\triangle \mathrm{SOC}$ to carbon input (Huang et al., 2007). The modeled $\triangle$ SOC for all the straw incorporation scenarios (Table 2) resulted in conversion coefficient values of $10.2-12.2 \%$ (given as averages over the $20 \mathrm{yr}$ period). These values fell in the range of $6-31 \%$ (mean: $15 \%$ ) from worldwide measurements in uplands with diverse climate, soil texture and SOC contents (Huang et al., 2007; and references therein). Meanwhile, they were particularly consistent with the conversion coefficient values (10.2-12.5\%) from the long-term field experiments at other field sites with similar climate, soil properties and management practices (adapted from Han et al., 2003 and Meng et al., 2005). The consistence suggests that our model simulation of $\triangle \mathrm{SOC}$ in this study was reliable.

Uncertainties relating to the simulation on $\mathrm{NH}_{3}$ volatilization and nitrate leaching may exist because the validation of $\mathrm{NH}_{3}$ volatilization was only based on a single fertilization event due to absence of year-round measurement and no validation of nitrate leaching due to no measurement. Nevertheless, the results of the $\mathrm{NH}_{3}$ volatilization and nitrate leaching from different management scenarios were comparable with previous studies. Specifically, the results from these scenarios excluding DCDI and DMPPI showed that 7-19\% of applied nitrogen were lost as $\mathrm{NH}_{3}$, which was comparable to the results of $0.6-18 \%$ from other field sites with similar climate, soil properties and fertilizer application methods (deep placement or surface broadcast followed by irrigation) in northern China (Zhang et al., 1992; Cai et al., 2002). The ratios of $\mathrm{NH}_{3}$ volatilization to applied nitrogen (26 and $29 \%$ ) for scenarios with nitrification inhibitors (DCDI and DMPPI) also fell within the range of 4-60\% from laboratory and field measurements worldwide (Kim et al., 2012; and references therein). Nitrate leaching was calculated to lose $10 \pm 7 \%$ (mean \pm standard deviation) of applied nitrogen from all scenarios, which was close to the value of $9 \pm 8 \%$ (mean \pm standard deviation) from an irrigated wheat-maize rotation field in northern China (adapted from Zhang et al., 2005). These comparable results give us more confidence in simulating the two goal variables.

There are three aspects we should pay attention to while using the model. The first one is how to deal with the input of tillage and fertilization if they occur on the same day. In northern China, like our case, basal fertilization and tillage usually occur on the same day with fertilizer surface broadcast immediately followed by tillage. DNDC model runs at a daily time step and tillage is supposed to occur before fertilization, which means that the fertilizer will not be incorporated into the soil by tillage if tillage and fertilization were set to occur on the same day. This will greatly influence $\mathrm{NH}_{3}$ volatilization and thus other nitrogen process (Cai et al., 2002). In order to solve this problem, we can simply set the tillage date one day later than fertilization (adopted in this study) or change the occurrence order of tillage and fertilization in the model. The second one is the soil moisture in winter. The output of soil moisture only include the unfrozen water, while the measurement of soil moisture include both the unfrozen water and ice, so we should add the modeled ice and unfrozen water to be the soil moisture and compare it with field measurement. The third one is the component of SOC in the model. The modeled SOC includes all the carbon pools, i.e., residues, microbes, humads and humus $(\mathrm{Li}$, 2000). However, the undecomposed residues are excluded when measuring SOC content in field experiments because they are not resistant to decomposition and thus cannot be regarded as SOC. So we only considered carbon pools of microbes, humads and humus as SOC in this study, and the annual change is $\triangle \mathrm{SOC}$. The original output of $\triangle \mathrm{SOC}$ is actually net ecosystem carbon balance (NECB), which is usually used as an estimate of $\triangle S O C$. However, our model result showed that there is a big difference between the NECB and $\triangle \mathrm{SOC}$ during the first several years of straw incorporation (Fig. 9), which implicates that the NECB does not equal to 


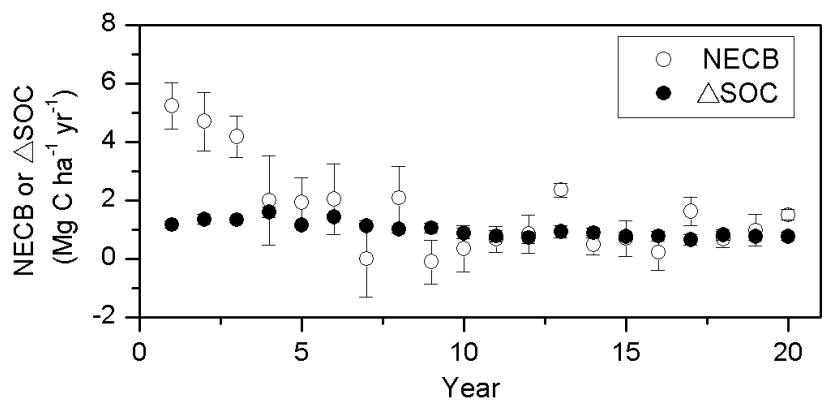

Fig. 9. Simulated net ecosystem carbon balance (NECB) and change in soil organic carbon $(\triangle \mathrm{SOC})$ over $20 \mathrm{yr}$ following the initiation of full residue incorporation. The given data points are means of the 13 scenarios (Table 2), excluding the one without crop straw incorporation, with vertical bars indicating the standard deviations.

$\Delta$ SOC under some circumstances. These three modifications are accessible to other sites and regions.

\subsection{Effects of alternative management practices on the goal variables}

Field experiment showed that straw incorporation increased $\mathrm{N}_{2} \mathrm{O}$ and $\mathrm{NO}$ emissions (Liu et al., 2011), while lack of simultaneous measurement for $\triangle \mathrm{SOC}$ and $\mathrm{CH}_{4}$ emission prevented us from judging whether straw incorporation should be popularized or not in the future. However, model result showed that increase of $\triangle \mathrm{SOC}$ compensated the increase of $\mathrm{N}_{2} \mathrm{O}$ emission and displayed a significant decrease of the NEGE (Fig. 8e), indicating a beneficial effect of straw incorporation in terms of greenhouse gas balance. Deep tillage is popularly adopted in the study area, but the fraction of the area with no-till practices in croplands increased from $3 \%$ in 2002 to $9 \%$ in 2009 in China (Yi, 2010). So a scenario of no tillage was set and the result showed that no-till practice gained the beneficial effects on most of the goal variables (Fig. 8). Although no-till practice had the beneficial effects, it is still hard to implement in the study region because no tillage requires specialized seeding equipment designed to plant seeds into undisturbed crop residues and soil, and purchasing new equipment (seed drills for example) is expensive. Besides, as with any production system, yields can drop if no-till isn't done correctly, so a combination of technique, equipment, pesticides, crop rotation, fertilization, and irrigation have to be used for specific local conditions (Raper et al., 2000). Use of nitrification inhibitors is demonstrated to have effectiveness in increasing crop nitrogen uptake, soil inorganic nitrogen stock and reducing $\mathrm{N}_{2} \mathrm{O}$ and $\mathrm{NO}$ emissions, with the effect of nitrification inhibitors on $\mathrm{NH}_{3}$ volatilization still unknown in our field experiment (Liu et al., 2013). The model result showed a great increase of $\mathrm{NH}_{3}$ volatilization (66 and $86 \%$ for DCDI and DMPPI, respectively) when nitrification inhibitors were used. These results imply that farmers should be cautious when using nitrification inhibitors in calcareous soils, although this practice can gain beneficial effects by reducing nitrogen losses from nitrate leaching and $\mathrm{N}_{2} \mathrm{O}$ and $\mathrm{NO}$ emissions.

Studies have showed that the measured nitrogen content in aboveground crop organs at harvest amounted to $404 \mathrm{~kg} \mathrm{Nha}^{-1} \mathrm{yr}^{-1}$ (Liu et al., 2013) to $427 \mathrm{~kg} \mathrm{~N} \mathrm{ha}^{-1} \mathrm{yr}^{-1}$ (Liu et al., 2012). Assuming $10 \%$ of nitrogen uptake by the crop remained in the roots (e.g., Huang et al., 2007), the total nitrogen needed to maintain the yields would be 448 $474 \mathrm{~kg} \mathrm{~N} \mathrm{ha}^{-1} \mathrm{yr}^{-1}$, which are very close to the locally conventional fertilizer dose of $430 \mathrm{~kg} \mathrm{Nha}^{-1} \mathrm{yr}^{-1}$ (ASI). This indicates the nitrogen application rate for ASI scenario is at a reasonable level. Increasing nitrogen application rate is usually regarded as an effective way to increase crop yield, however, when fertilizer application rate reached a threshold, further increase of nitrogen application rate will not increase crop yield any more (Jensen and Schjoerring, 2011). In order to know this threshold in our study, we set scenarios of increasing or decreasing nitrogen application rate from that of ASI, therefore we had nitrogen application levels ranging from 301 to $559 \mathrm{~kg} \mathrm{~N} \mathrm{ha}^{-1} \mathrm{yr}^{-1}$ (Table 2). Model result showed a threshold of approximately $366 \mathrm{~kg} \mathrm{~N}$ ha yr$^{-1}$, which is $15 \%$ lower than the current level. Nitrogen losses via nitrate leaching, $\mathrm{NH}_{3}$ volatilization and $\mathrm{N}_{2} \mathrm{O}$ and $\mathrm{NO}$ emissions increased with the increase of nitrogen fertilizer application rate (Fig. 8c-e), which implies that the lower nitrogen application rate the better as long as crop yield can be sustained. No further increase of crop yield in response to increase of nitrogen application rate was due to water limitation in our study, which was proven by the significant increase of crop yield for IRRindex scenario in comparison with ASI scenario. Although the annual irrigation amount was approximately the same for IRRindex and ASI scenarios, irrigation occurred many times according to crop demand for IRRindex scenario but with fixed times for ASI scenario. This suggests that the bottleneck of increasing crop yield in the study area is how to effectively irrigate the field rather than blindly increase nitrogen fertilizer use.

\subsection{Uncertainties of the best management practice}

With regard to the newly established method (the objective method) for identifying BMP, as Eq. (4) shows, the parameters (c-f) which were determined according to the costs of $\mathrm{N}$-related impacts or mitigation in USA may be different in China. This can cause uncertainties of $I$ value and thus BMP. However, the costs of N-related impacts or mitigation in China is yet unavailable, so we have to use the results in USA temporarily. The Assessment index (I) only includes the comprehensive effects of the goal variables; while other factors (e.g., cost of operating management practices, technical feasibility, the acceptability of the management practices by local farmers) are not included. Considering the complexity and difficulty of incorporating these factors into the assessment index $(I)$, we decided to set constraints in 
conjunction with $I$ value to identify BMP. The constraints were set according to specific local conditions. Uncertainties of BMP can arise if constraints are not set properly. Therefore, one should be quite cautious of determining the constraints. The BMP chosen by this objective method, i.e., the Imp2, was the same as that by the subjective method. In comparison however, the new approach can be more easily programmed, automatically implemented and is expected to apply for more complex cases at site or regional scales, as long as the process-oriented model performs well for simulating the goal variables.

\section{Conclusions}

The denitrification-decomposition (DNDC) model was firstly validated with the simultaneous observations at a wheat-maize cropping site in northern China and then used to assess the biogeochemical effects of different management practices on multiple goals of crop yields, net emission of greenhouse gases in the ecosystem (NEGE), nitric oxide $(\mathrm{NO})$ emission, ammonia $\left(\mathrm{NH}_{3}\right)$ volatilization and nitrate leaching. Observations used for model validation included soil moisture and temperature, crop yields, aboveground biomass and fluxes of net ecosystem exchange of carbon dioxide, methane, nitrous oxide $\left(\mathrm{N}_{2} \mathrm{O}\right)$, $\mathrm{NO}$ and $\mathrm{NH}_{3}$. The consistence between the simulated and observed results implies that the DNDC model simulation result is reliable. Simulated results from different management practice scenarios suggest that cautiousness about the use of nitrification inhibitors in calcareous soils must be warranted due to its stimulatory effect on $\mathrm{NH}_{3}$ volatilization. Nitrate leaching, $\mathrm{NH}_{3}$ volatilization, $\mathrm{N}_{2} \mathrm{O}$ and $\mathrm{NO}$ emissions increased with the increase of nitrogen application rate, implying that the lower nitrogen dose the better as long as crop yield can be sustained. A $15 \%$ reduction of nitrogen dose from the current use ( $\left.430 \mathrm{~kg} \mathrm{Nha}^{-1}\right)$ will not decrease crop yield in our study. The bottleneck of increasing crop yield in the study area is how to effectively irrigate the field rather than blindly increase nitrogen fertilizer use. To determine the best management practice (BMP) from the simulated results of management practice scenarios, two methods were used. Both methods got the same BMP. The BMP followed the management practices of the current crop cultivar and field operation schedules, full straw incorporation, reduction of nitrogen dose and irrigation water by 15 and $25 \%$, respectively, than the current use.

\section{Supplementary material related to this article is available online at http://www.biogeosciences.net/11/91/ 2014/bg-11-91-2014-supplement.pdf.}

Acknowledgements. This study was financially supported by the Ministry of Sciences and Technology of China (2012CB417100), the Ministry of Agriculture of China (201103039) and the National Natural Science Foundation of China (41021004). We sincerely thank Changsheng Li for his substantial help by providing the DNDC model and technical instruction and Yongqiang Yu for his aid.

Edited by: A. Neftel

\section{References}

Aneja, V. P., Roelle, P. A., Murray, G. C., Southerland, J., Erisman, J. W., Fowler, D., Asman, W. A. H., and Patni, N.: Atmospheric nitrogen compounds II: emissions, transport, transformation, deposition and assessment, Atmos. Environ., 35, 1903-1911, 2001.

Aronson, E. and Helliker, B.: Methane flux in non-wetland soils in response to nitrogen addition: a meta-analysis, Ecology, 91, 3242-3251, 2010.

Babu, Y. J., Li, C., Frolking, S., Nayak, D., and Adhya, T.: Field validation of DNDC model for methane and nitrous oxide emissions from rice-based production systems of India, Nutr. Cycl. Agroecosys., 74, 157-174, 2006.

Baggs, E. M., Stevenson, M., Pihlatie, M., Regar, A., Cook, H., and Cadisch, G.: Nitrous oxide emissions following application of residues and fertiliser under zero and conventional tillage, Plant Soil, 254, 361-370, 2003.

Birch, M. B. L., Gramig, B. M., Moomaw, W. R., Doering III., O. C., and Reeling, C. J.: Why metrics matter: evaluating policy choices for reactive nitrogen in the Chesapeake Bay Watershed, Environ. Sci. Technol., 45, 168-174, 2011.

Bodelier, P. L. E. and Laanbroek, H. J.: Nitrogen as a regulatory factor of methane oxidation in soils and sediments, FEMS Microbiol. Ecol., 47, 265-277, 2004.

Brown, L., Syed, B., Jarvis, S., Sneath, R., Phillips, V., Goulding, K., and Li, C.: Development and application of a mechanistic model to estimate emission of nitrous oxide from UK agriculture, Atmos. Environ., 36, 917-928, 2002.

Cai, G., Chen, D., Ding, H., Pacholski, A., Fan, X., and Zhu, Z.: Nitrogen losses from fertilizers applied to maize, wheat and rice in the North China Plain, Nutr. Cycl. Agroecosys., 63, 187-195, 2002.

Cai, Z., Sawamoto, T., Li, C., Kang, G., Boonjawat, J., Mosier, A., Wassmann, R., and Tsuruta, H.: Field validation of the DNDC model for greenhouse gas emissions in East Asian cropping systems, Global Biogeochem. Cy., 17, 1107, doi:10.1029/2003GB002046, 2003.

Compton, J. E., Harrison, J. A., Dennis, R. L., Greaver, T. L., Hill, B. H., Jordan, S. J., Walker, H., and Campbell, H. V.: Ecosystem services altered by human changes in the nitrogen cycle: a new perspective for US decision making, Ecol. Lett., 14, 804-815, 2011.

Cui, F., Yan, G., Zhou, Z., Zheng, X., and Deng, J.: Annual emissions of nitrous oxide and nitric oxide from a wheat-maize cropping system on a silt loam calcareous soil in the North China Plain, Soil Biol. Biochem., 48, 10-19, 2012.

Di, H. and Cameron, K.: The use of a nitrification inhibitor, dicyandiamide (DCD), to decrease nitrate leaching and nitrous oxide 
emissions in a simulated grazed and irrigated grassland, Soil Use Manage., 18, 395-403, 2002.

Dodds, W. K., Bouska, W. W., Eitzmann, J. L., Pilger, T. J., Pitts, K. L., Riley, A. J., Schloesser, J. T., and Thornbrugh, D. J.: Eutrophication of U.S. freshwaters: analysis of potential economic damages, Environ. Sci. Technol., 43, 12-19, 2009.

Dutaur, L. and Verchot, L. V.: A global inventory of the soil $\mathrm{CH}_{4}$ sink, Global Biogeochem. Cy., 21, GB4013, doi:10.1029/2006GB002734, 2007.

Estavillo, J. M., Merino, P., Pinto, M., Yamulki, S., Gebauer, G., Sapek, A., and Corre, W.: Short term effect of ploughing a permanent pasture on $\mathrm{N}_{2} \mathrm{O}$ production from nitrification and denitrification, Plant Soil, 239, 253-265, 2002.

EPA: Air Quality Criteria for Particulate Matter, Volumes I and II (EPA Publication Nos. EPA-600-P-99-002aF, EPA-600-P-99002bF), Research Triangle Park, NC, US EPA, available at: http: //cfpub.epa.gov/ncea/cfm/recordisplay.cfm?deid=87903 (last access date: 18 October 2007), 2004.

Farahbakhshazad, N., Dinnes, D. L., Li, C., Jaynes, D. B., and Salas, W.: Modeling biogeochemical impacts of alternative management practices for a row-crop field in Iowa, Agr. Ecosyst. Environ., 123, 30-48, 2008.

Francisco, S. S., Urrutia, O., Martin, V., Peristeropoulos, A., and Garcia-Mina, J. M.: Efficiency of urease and nitrification inhibitors in reducing ammonia volatilization from diverse nitrogen fertilizers applied to different soil types and wheat straw mulching, J. Sci. Food Agr., 91, 1569-1575, 2011.

Galloway, J. N., Hiram Levy, I., and Kasibhatla, P. S.: Year 2020: consequences of population growth and development on deposition of oxidized nitrogen, Ambio, 23, 120-123, 1994.

Giltrap, D. L., Li, C. S., and Saggar, S.: DNDC: A process-based model of greenhouse gas fluxes from agricultural soils, Agr. Ecosyst. Environ., 136, 292-300, 2010a.

Giltrap, D. L., Singh, J., Saggar, S., and Zaman, M.: A preliminary study to model the effects of a nitrification inhibitor on nitrous oxide emissions from urine-amended pasture, Agr. Ecosyst. Environ., 136, 310-317, 2010b.

Goulding, K.: Nitrate leaching from arable and horticultural land, Soil Use Manage., 16, 145-151, 2000.

Grandy, A. S., Parr, S., Robertson, G. P., and Loecke, T. D.: Longterm trends in nitrous oxide emissions, soil nitrogen, and crop yields of till and no-till cropping systems, J. Environ. Quality, 35, 1487-1495, 2006.

Han, Z. Q., Zhang, D. X., Chen, H. B., and Chang, L. S.: The evolvement rule of soil's organic matter quality under the condition of long-term and oriented fertilization of wheat-corn rotation system, J. H. B. Vocation-Tec. Tch. Col., 17, 10-14, 2003 (in Chinese with English abstract)

Huang, Y., Zhang, W., Sun, W., and Zheng, X.: Net primary production of Chinese croplands from 1950 to 1999, Ecol. Appl., 17, 692-701, 2007.

Huang, Y., Yu, Y., Zhang, W., Sun, W., Liu, S., Jiang, J., Wu, J., Yu, W., Wang, Y., and Yang, Z.: Agro-C: A biogeophysical model for simulating the carbon budget of agroecosystems, Agr. Forest Meteorol., 149, 106-129, 2009.

IPCC: Climate Change 2007: The Physical Science Basis, Contribution of Working Group I to the Fourth Assessment Report of the Intergovernmental Panel on Climate Change, edited by: Solomon, S., Qin, D., Manning, M., Chen, Z., Marquis, M., Av- eryt, K. B., Tignor, M., and Miller, H. L., Cambridge Univ. Press, New York., 2007.

Jensen, L. S., Schjoerring, J. K.: Benefits of nitrogen for food, fibre and industrial production, in: The European Nitrogen Assessment, edited by: Mark, A. S., Clare, M. H., Jan, W. E., Gilles, B., Albert, B., Peringe, G., Hans, V. G., and Bruna, G., Cambridge University Press, UK, 32-61, 2011.

Jia, L., Buerkert, A., Chen, X., Römheld, V., and Zhang, F.: Lowaltitude aerial photography for optimum $\mathrm{N}$ fertilization of winter wheat on the North China Plain, Field Crops Res., 89, 389-395, 2004.

Jiang, D., Zhuang, D., Fu, J., Huang, Y., and Wen, K.: Bioenergy potential from crop residues in China: Availability and distribution, Renew. Sust. Energ. Rev., 16, 1377-1382, 2012.

Ju, X. T., Xing, G. X., Chen, X. P., Zhang, S. L., Zhang, L. J., Liu, X. J., Cui, Z. L., Yin, B., Christie, P., and Zhu, Z. L.: Reducing environmental risk by improving $\mathrm{N}$ management in intensive Chinese agricultural systems, P. Natl. Acad. Sci., 106, 3041-3049, 2009.

Kesik, M., Ambus, P., Baritz, R., Brüggemann, N., ButterbachBahl, K., Damm, M., Duyzer, J., Horváth, L., Kiese, R., Kitzler, B., Leip, A., Li, C., Pihlatie, M., Pilegaard, K., Seufert, S., Simpson, D., Skiba, U., Smiatek, G., Vesala, T., and ZechmeisterBoltenstern, $\mathrm{S}$.: Inventories of $\mathrm{N}_{2} \mathrm{O}$ and $\mathrm{NO}$ emissions from $\mathrm{Eu}-$ ropean forest soils, Biogeosciences, 2, 353-375, doi:10.5194/bg2-353-2005, 2005.

Kim, D. G., Saggar, S., and Roudier, P.: The effect of nitrification inhibitors on soil ammonia emissions in nitrogen managed soils: a meta-analysis, Nutr. Cycl. Agroecosys., 93, 51-64, 2012.

Li, C., Frolking, S., and Frolking, T. A.: A model of nitrous oxide evolution from soil driven by rainfall events: 1 . Model structure and sensitivity, J. Geophys. Res., 97, 9759-9776, 1992.

Li, C., Narayanan, V., and Harriss, R. C.: Model estimates of nitrous oxide emissions from agricultural lands in the United States, Global Biogeochem. Cy., 10, 297-306, 1996.

Li, C. S.: Modeling trace gas emissions from agricultural ecosystems, Nutr. Cycl. Agroecosys., 58, 259-276, 2000.

Li, H., Qiu, J., Wang, L., Tang, H., Li, C., and Van Ranst, E.: Modelling impacts of alternative farming management practices on greenhouse gas emissions from a winter wheat-maize rotation system in China, Agr. Ecosyst. Environ., 135, 24-33, 2010.

Li, Y., White, R., Chen, D., Zhang, J., Li, B., Zhang, Y., Huang, Y., and Edis, R.: A spatially referenced water and nitrogen management model (WNMM) for (irrigated) intensive cropping systems in the North China Plain, Ecol. Model., 203, 395-423, 2007.

Liang, Y., Chen, C., Xue, Q., Lin, X., and Peng, Q.: Long-term Soil Organic Carbon and Crop Yield Dynamics on Cropland in Hilly and Gully Areas of Loess Plateau, J. Agronom., 10, 40-47, 2011.

Liu, C., Yu, J., and Kendy, E.: Groundwater exploitation and its impact on the environment in the North China Plain, Water Int., 26, 265-272, 2001.

Liu, C., Wang, K., Meng, S., Zheng, X., Zhou, Z., Han, S., Chen, D., and Yang, Z.: Effects of irrigation, fertilization and crop straw management on nitrous oxide and nitric oxide emissions from a wheat-maize rotation field in northern China, Agr. Ecosyst. Environ., 140, 226-233, 2011.

Liu, C., Wang, K., and Zheng, X.: Responses of $\mathrm{N}_{2} \mathrm{O}$ and $\mathrm{CH}_{4}$ fluxes to fertilizer nitrogen addition rates in an irrigated wheatmaize cropping system in northern China, Biogeosciences, 9, 839-850, doi:10.5194/bg-9-839-2012, 2012. 
Liu, C., Wang, K., and Zheng, X.: Effects of nitrification inhibitors (DCD and DMPP) on nitrous oxide emission, crop yield and nitrogen uptake in a wheat-maize cropping system, Biogeosciences, 10, 2427-2437, doi:10.5194/bg-10-2427-2013, 2013.

Liu, J. and Diamond, J.: China's environment in a globalizing world, Nature, 435, 1179-1186, 2005.

Liu, J. and Diamond, J.: Revolutionizing China's environmental protection, Science, 319, 37-38, 2008.

Loague, K. and Green, R. E.: Statistical and graphical methods for evaluating solute transport models: overview and application, J. Contam. Hydrol., 7, 51-73, 1991.

Ludwig, B., Bergstermann, A., Priesack, E., and Flessa, H.: Modelling of crop yields and $\mathrm{N}_{2} \mathrm{O}$ emissions from silty arable soils with differing tillage in two long-term experiments, Soil Till. Res., 112, 114-121, 2011.

Mei, B., Zheng, X., Xie, B., Dong, H., Zhou, Z., Wang, R., Deng, J., Cui, F., Tong, H., and Zhu, J.: Nitric oxide emissions from conventional vegetable fields in southeastern China, Atmos. Environ., 43, 2762-2769, 2009.

Meng, L., Cai, Z. C., and Ding, W. X.: Carbon contents in soils and crops as affected by long-term fertilization, Acta Pedolog. Sin., 42, 769-776, 2005 (in Chinese with English abstract).

Miehle, P., Livesley, S., Feikema, P., Li, C., and Arndt, S.: Assessing productivity and carbon sequestration capacity of Eucalyptus globulus plantations using the process model Forest-DNDC: Calibration and validation, Ecol. Model., 192, 83-94, 2006.

Parton, W., Schimel, D., Ojima, D., Cole, C. V., Bryant, R., and Arnold, R.: A general model for soil organic matter dynamics: sensitivity to litter chemistry, texture and management, Soil Sci. Soc. Am. SP, 39, 147-167, 1994.

Raper, R., Reeves, D., Burmester, C., and Schwab, E.: Tillage depth, tillage timing, and cover crop effects on cotton yield, soil strength, and tillage energy requirements, Appl. Eng. Agric., 16, 379-385, 2000.

Roelcke, M., Li, S. X., Tian, X. H., Gao, Y. J., and Richter, J.: In situ comparisons of ammonia volatilization from $\mathrm{N}$ fertilizers in Chinese loess soils, Nutr. Cycl. Agroecosys., 62, 73-88, 2002.

Schlesinger, W. H.: Carbon sequestration in soils, Science, 284, 2095, doi:10.1126/science.2284.5423.2095, 1999

Seitzinger, S.: Nitrogen cycle: Out of reach, Nature, 452, 162-163, 2008.

Smith, P., Smith, J. U., Powlson, D. S., McGill, W. B., Arah, J. R. M., Chertov, O. G., Coleman, K., Franko, U., Frolking, S., Jenkinson, D. S., Jensen, L. S., Kelly, R. H., Klein-Gunnewiek, H., Komarov, A. S., Li, C., Molina, J. A. E., Mueller, T., Parton, W. J., Thornley, J. H. M., and Whitmore, A. P.: A comparison of the performance of nine soil organic matter models using datasets from seven long-term experiments, Geoderma, 81, 153225, 1997.

Tilman, D., Cassman, K. G., Matson, P. A., Naylor, R., and Polasky, S.: Agricultural sustainability and intensive production practices, Nature, 418, 671-677, 2002.

Tong, C., Hall, C. A. S., and Wang, H.: Land use change in rice, wheat and maize production in China (1961-1998), Agr. Ecosyst. Environ., 95, 523-536, 2003.

Tonitto, C., Li, C., Seidel, R., and Drinkwater, L.: Application of the DNDC model to the Rodale Institute Farming Systems Trial: challenges for the validation of drainage and nitrate leaching in agroecosystem models, Nutr. Cycl. Agroecosys., 87, 483-494, 2010.

van Grinsven, H., Rabl, A., and de Kok, T.: Estimation of incidence and social cost of colon cancer due to nitrate in drinking water in the EU: a tentative cost-benefit assessment, Environ. Health, 9, 58, doi:10.1186/1476-069X-9-58, 2010.

Wang, E., Yu, Q., Wu, D., and Xia, J.: Climate, agricultural production and hydrological balance in the North China Plain, Int. J. Climatol., 28, 1959-1970, 2008.

Wang, J. Y., Cardenas, L. M., Misselbrook, T. H., Cuttle, S., Thorman, R. E., and Li, C.: Modelling nitrous oxide emissions from grazed grassland systems, Environ. Pollut., 162, 223-233, 2012.

Wang, K., Liu, C., Zheng, X., Pihlatie, M., Li, B., Haapanala, S., Vesala, T., Liu, H., Wang, Y., Liu, G., and Hu, F.: Comparison between eddy covariance and automatic chamber techniques for measuring net ecosystem exchange of carbon dioxide in cotton and wheat fields, Biogeosciences, 10, 6865-6877, doi:10.5194/bg-10-6865-2013, 2013.

Yan, X., Akimoto, H., and Ohara, T.: Estimation of nitrous oxide, nitric oxide and ammonia emissions from croplands in East, Southeast and South Asia, Glob. Change Biol., 9, 1080-1096, 2003.

Yang, Z., Turner, D., Zhang, J., Wang, Y., Chen, M., Zhang, Q., Denmead, O., Chen, D., and Freney, J.: Loss of nitrogen by ammonia volatilisation and denitrification after application of urea to maize in Shanxi Province, China, Soil Res., 49, 462-469, 2011.

Yao, Z., Zheng, X., Xie, B., Mei, B., Wang, R., Butterbach-Bahl, K., Zhu, J., and Yin, R.: Tillage and crop residue management significantly affects $\mathrm{N}$-trace gas emissions during the non-rice season of a subtropical rice-wheat rotation, Soil Biol. Biochem., 41, 2131-2140, 2009.

Yi, Z.: The Yearbook of Agricultural Mechanization in China. China Agricultural Science and Technology Press, Beijing, 2010.

Zhang, F., Li, C., Wang, Z., and Wu, H.: Modeling impacts of management alternatives on soil carbon storage of farmland in Northwest China, Biogeosciences, 3, 451-466, doi:10.5194/bg-3-4512006, 2006.

Zhang, S., Cai, G., Wang, X., Zhu, Z., and Freney, J.: Losses of Urea-Nitrogen Applied to Maize Grown on a Calcareous FluvoAquic Soil in North China Plain, Pedosphere, 2, 171-178, 1992.

Zhang, Y. M., Hu, C. S., Zhang, J. B., Chen, D. L., and Li, X. X.: Nitrate leaching in an irrigated wheat-maize rotation field in the North China Plain, Pedosphere, 15, 196-203, 2005.

Zhao, R. F., Chen, X. P., Zhang, F. S., Zhang, H., Schroder, J., and Romheld, V.: Fertilization and nitrogen balance in a wheat-maize rotation system in North China, Agronom. J., 98, 938-945, 2006.

Zhao, R. F., Chen, X. P., and Zhang, F. S.: Nitrogen cycling and balance in winter wheat - summer maize rotation system in Northern China Plain, Acta Pedolog. Sin., 46, 684-697, 2009 (in Chinese with English abstract).

Zhu, Z. and Chen, D.: Nitrogen fertilizer use in China - Contributions to food production, impacts on the environment and best management strategies, Nutr. Cycl. Agroecosys., 63, 117-127, 2002. 